\title{
THE EFFECT OF GROWTH HORMONE TREATMENT ON GROWTH IN ZINC DEFICIENT RATS
}

\author{
Dana L. Dicks \\ School of Dietetics and Human Nutrition \\ MacDonald Campus of \\ MCGill University, Montreal \\ October, 1992
}

\begin{abstract}
A Thesis submitted to the Faculty of Graduate studies and Research in partial fulfillment of the requirements for the degree of Masters of Science
\end{abstract}

(C) Dana L. Dicks

1992 


\section{ACXNONLEDGEMENTS}

The financial support of NSERC Canada for this project is gratefully acknowledged.

I would like to thank my supervisor, Dr. Arezoo Rojhani, for her advice, guidance, and support during this project.

I would also like to thank $\mathrm{Dr} S$. Kubow and Dr. E. Block for serving on my thesis committee.

Many thanks to Ming Cha for his assistance both in animal care and handling as well as in the lab.

A special thank you to susan Smith for her help and advice throughout the project. Thank you for answering my many questions.

I would also like to thank Aghdas Zamani for her technical assistance.

A very special thank you to the Kinship Group at St. George's church for their love, support, and prayers during my stay at MacDonald College. You've all earned part of this degree too.

Finally, I would especially like to thank Tony Grainger, Joan Austen, and Christine Finlayson for their love, prayers, and encouragement. Thank you for always having the time to listen. 


\section{AB8TRACT}

The ability of human growth hormone (hGH) to alleviate the effects of zinc deficiency on growth was investigated in the rat. Human $G H$ treatment had no significant effect on food consumption, growth parameters or plasma IGF-I. Food consumption, tail length, liver weight, and tibia weight were significntly lower in the zinc deficient group. Body weight was significantly reduced in the zinc deficient and pair fed groups compared to the control. A significant interaction between $z$ inc and hGH was found for tibial epiphyseal cartilage width but there were no significant differences between the groups receiving $\mathrm{hGH}$ and the respective shams. Plasma IGF-I was numerically lower in the zinc deficient rats compared to the paix fed rats but this difference did not reach statistical significance. Tissue zinc content and plasma alkaline phosphatase were significantly decreased by the dietary zinc deficiency. Plasma zinc was higher in the groups receiving hGH. Significant interactions between $z$ inc and hGH was found for liver iron, tibial zinc, and tibial copper. Copper and iron showed a competitive interaction with zinc and were lower in the rats receiving the control diet. Both lowered $z$ inc and food intake contributed to the effects of the zinc deficiency; however, these effects were not equally distributed. Food intake had the greater effect on growth and plasma IGF-I while tissue mineral content showed a greater effect for zinc intake. 


\section{REBOxt5}

On a étudié la capacité de la somatotrophine humaine a atténuer les effets d'une carence en $z$ inc sur la croissance du rat. Un traitement à la somatotrophine humaine n'a eu aucun effet significatif sur la consommation d'aliments, les paramètres de croissance ou l'IGF-I. La consommation d'aliments, la longueur de la queue, le poids du foie et le poids du tibia étaient nettement inférieurs dans le groupe qui affichait une carence en zinc. Le poids corporel etait nettement plus bas chez les sujets souffrant d'une carence en zinc et chez les animaux témoins recevant une alimentation identique par rapport au groupe témoin de l'etude dont les animaux étaient nourris à volonté. On a noté une interaction significative entre le zinc et la somatotrophine pour ce qui est de la largeur du cartilage épiphysaire du tibia, mais on $n^{\prime}$ a observé aucune différence significative entre les groupes recevant de la somatotrophine humaine et les sujets témoins qui leur étaient appariés. Le taux d'IGF-I plasmatique était inférieur chez les rats présentant une carence en zinc et les rats nourris de façon identique, mais cette différence ne revêtait pas d'importance statistique. La teneur en $z$ inc des tissus et la phosphatase alcaline plasmatique ont affiché une diminution marquée liée à une alimentation pauvre en zinc. Les taux de zinc plasmatiques étaient plus élevés dans les groupes qui recevaient de la somatotrophine humaine. On a noté des interactions significatives entre le zinc et la 
somatotrophine humaine au niveau du fer hépatique, du zinc du tibia et du cuivre du tibia. On a observé une interaction compétitive du cuivre et du fer avec le zinc et ces taux ont été moins élevés chez les rats qui ont reçu le régime de référence. La réduction de l'apport de zinc ainsi qu'une diminution de la ration alimentaire ont contribué a la carence en zinc; toutefois, ces effets n'ont pas eté répartis également. L'alimentation a été le facteur qui a le plus influé sur la croissance et l'IGF-I plasmatique tandis que la teneur en mineraux des tissus a fait apparaitre un effet plus marqué de la prise de zinc. 
Title Page..............................

Acknowledgements......................... ii

Abstract............................. ii

Table of Contents......................... vi

List of Tables........................... ix

List of Figures........................

List of Appendices........................ xi

Introduction............................ 1

Chapter I. Literature Review.................. 2

II. Overview of zinc Nutriture.............. 2

A. Distribution....................... 3

B. Absorption......................... 3

C. Excretion........................4 4

D. Metabolism....................... 5

III. Zinc Deficiency in the Rat.............. 7

IV. Zine Deficiency in Humans............... 9

v. The Somatomedin Hypothesis and Growth........ 12

A. Growth Hormone.................... 12

B. Insulin-like Growth Factors............. 13

c. The Somatomedin Hypothesis............ 15

VI. Nutritional Regulation of IGF-I........... 24

VII. Zinc, Growth Hormone, and IGF-I........... 29

Statement of Purpose...................... 36

Chapter II. Materials and Methods............... 38

I. Experimental Design.................. 38 
II. Experimental Protocol.................. 39

III. Experimental Techniques................. 39

A. Animal Care......................... 39

B. Human Growth Hormone (hGH) Treatment........ 40

c. Diets...........................41

D. Tissue Collection....................4 41

IV. Analytical Procedures.................. 42

A. Tibial Epiphyseal Cartilage Width..........42

B. Plasma Human Growth Hormone............. 43

C. Plasma Insulin-like Growth Factor I........ 43

D. Plasma Zinc and Alkaline Phosphatase........43

E. Tibia and Liver Trace Element Analysis....... 44

v. Statistical Analyses................... 44

Chapter III. Results..................... 50

I. Food Intake and Growth Parameters........... 50

A. Food Intake...................... 50

B. Body Weight Gain.................... 51

C. Tail Length....................... 51

D. Liver and Tibia Weight............... 52

C. Tibial Epiphyseal Cartilage Width......... 52

II. Plasma Values..................... 53

A. Plasma zinc......................... 53

B. Plasma Alkaline Phosphatase............. 53

C. Plasma Insulin-like Growth Factor I........ 54

D. Human Growth Hormone............... $5 t_{k}$

III. Tissue Mineral Content................ 54 
A. Liver $\operatorname{zinc} . \ldots \ldots \ldots \ldots \ldots \ldots \ldots \ldots \ldots \ldots \ldots$

B. Liver Copper..................... 55

C. Liver Iron...................... 55

D. Tibial zinc........................ 55

E. Tibial Copper..................... 56

Chapter IV. Discussion....................665

I. Nutritional status of the Rat.............66 65

II. Plasma Insulin-like Growth Factor I.......... 74

III. Effect of hGH...................... 76

IV. Summary $\ldots \ldots \ldots \ldots \ldots \ldots \ldots \ldots \ldots \ldots \ldots \ldots \ldots \ldots$

v. Conclusion........................ 81

Appendix............................... 83

Bibliography.............................. 94 


\section{LI8T OF TABLEB}

2.1. Zinc Deficient Diet....................46

2.2. Zinc Control Diet......................47

2.3. AIN-76 vitamin Mixture................... 48

2.4. AIN-76 Mineral Mixture without zinc........... 49

3.1. The effect of $z$ inc and hGH in food intake and growth parameters................... 57

3.2. The effect of $\mathrm{zinc}$ and hGH on plasma values...... 59

3.3. The effect of $z$ inc and hGH on tissue mineral content........................60 60 


\section{LI8T OF FIGUREB}

1.1. Regulation of somatomedin $($ IGF-I) $\ldots \ldots \ldots \ldots \ldots \ldots 17$

1.2. Activities of somatomedins (IGF-I) ........... 25

1.3. Nutritional regulation of the GH/IGF-I/

IGF binding protein cascade............... 28

2.1. Experimental Design.................... 38

3.1. Cumulative Food Intake - Effect of Dietary zinc... 61

3.2. Daily Food Intake - Effect of Dietary Zinc.......62

3.3. Cumulative Body Weight - Effect of Dietary Zinc... 63

3.4. Cumulative Tail Length - Effect of Dietary Zinc... 64

4.1. Photograph.......................... 68 
LIST OF APPENDICES

Appendix 1. Determination of zinc in the Diet.......83

Appendix 2. Epiphyseal Cartilage width Assay........ 84

Appendix 3. Acid Extraction of IGF-I

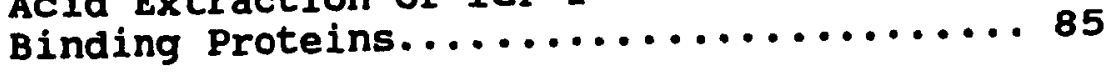

Appendix 4. Fat Extraction of the Tibia............ 86

Appendix 5. Determination of Trace Elements........ 86

Appendix 6. Statistical Methods................ 88

Appendix 7. Summary of significant statistics....... 89

$\mathbf{x i}$ 
INTHODUCTIOA

Raulin (1869) first demonstrated the importance of zinc for a biological system when he reported that $z$ inc was essential for the growth of Aspergillus niger. Sixty-five years later, Todd et al. (1934) demonstrated the essentiality of zinc for the rat. During the 1950's, Tucker and Salmon (1955) showed that zinc cured and prevented parakeratosis in swine while o'Dell et al. (1958) found zinc to be essential for the chicken. In the early 1960's, studies in the Middle East provided the first evidence for the occurrence of a nutritional deficiency of $z$ inc in humans (Prasad ets al., 1963). While the importance of zinc for growth and development has been demonstrated, the exact mechanisms have yet to be established. One possible mechanism is an adverse effect of zinc deficiency on the generation of insulin-like growth factor I (IGF-I), a growth factor believed to mediate some of the effects of growth hormone (GH) on longitudinal growth (Cossack, 1986; 1988). Growth hormone is also the major regulator of circulating IGF-I. The objective of the present study was to examine the efficacy of $\mathrm{GH}$ treatment to alleviate the adverse effects of zinc deficiency on growth in the rat. 


\section{OVERTIEN OF RINC NOTRITURE}

Health and Welfare Canada (1990) recently published the revised nutrition recommendations for Canadians. Recommended intakes for zinc were as follows: $12 \mathrm{mg} /$ day for males, 9 $\mathrm{mg} /$ day for females, and $15 \mathrm{mg} /$ day for pregnant and lactating females. Based on the zinc content of breast milk, $2 \mathrm{mg} / \mathrm{day}$ was suggested for infants aged 0-4 months. No firm recommendations were established for older children since available data was believed to be inadequate. Food sources of zinc include red meat, liver, egg yolk, shellfish, poultry, milk, cheese, and whole grains with zinc from animal sources being more readily available. The mixed Canadian diet provides approximately $5 \mathrm{mg}$ of zinc per $1000 \mathrm{kcal}$ with about one-half derived from meat, fish, and poultry (Srivistava et al., 1977). More recently, Smit Vanderkooy and Gibson (1987) showed an average zinc intake of $4.6 \pm 1.0 \mathrm{mg} / 1000 \mathrm{kcal}$ for Canadian preschool children. The suboptimal zinc status of boys in this study was associated with decreased zinc intake from animal sources. While animal foods are important sources of zinc for affluent countries, less developed countries depend upon grains which have a high phytate and phosphate content (Prasad, 1988). Prasad stated that the "predominant use of cereal proteins by the majority of the world's population is an important predisposing factor for zinc deficien- 
cy" .

\section{DIBTRIBUTION}

The estimated zinc content of a standard $70 \mathrm{~kg}$ man is approximately 1.5-2 $\mathrm{g}$ (Prasad, 1982). It is present in all organs, tissues, fluids, and secretions of the body with average $z$ inc concentrations ranging from $1-150 \mu \mathrm{g} / \mathrm{g}$ wet weight (Jackson, 1989). Skeletal muscle contains the greatest portion of body zinc because of its large mass. Muscle and bone together account for more than $80 \%$ of the total body zinc. The liver, kidney, retina, and prostate also have high concentrations of zinc. Plasma zinc represents approximately $0.1 \%$ of total body zinc. Most plasma zinc is bound to albumin although other plasma proteins can bind significant amounts (Prasad, 1982; Jackson, 1989).

There is little information regarding the distribution of zinc within tissues and the nature of its intracellular binding (Jackson, 1989). Small amounts of zinc can be found within all organelles of the cell which corresponds to the wide distribution of zinc-containing enzymes. Within the cell, zinc appears to be bound to proteins with the affinity for zinc varying among the different proteins. It is unclear whether substantial amounts of free zinc or zinc bound to amino acids exist within the cell. The susceptibility of various subcellular fractions to zinc depletion is unknown.

\section{AB8ORPTION}

Approximately 10-40z of dietary zinc is available for 
absorption (Solomons, 1982). The exact sites of absorption are unknown although the majority probably occurs in the duodenum and ileum (Hambidge et al., 1986). Information on the mechanism of absorption, whether it be passive, active, or facultative transport, is also scarce (Prasad, 1982). Factors affecting zinc absorption include body size, zinc status, level of zinc in the diet, and presence in the diet of potential inhibiting substances such as phosphate, phytate, fiber, or chelating agents. Cousins (1979) proposed a fourphase model to explain the intestinal absorption of zinc: uptake by the intestinal cell, movement through the mucosal cell, transfer to the portal circulation, and secretion of endogenous $z$ inc back into the intestinal cell.

zinc absorbed in the intestine is carried to the liver in the portal plasma bound to albumin (Hambidge et al., 1986). The liver is the major organ involved in zinc metabolism and contains various zinc binding components of different molecular weights and lability, including metallothionein. About 30-40\% of the zinc entering the liver is released back into the blood. The circulating zinc is then incorporated into various extrahepatic tissues. Entry of zinc into the cells occurs in two phases: an early, rapid uptake that is saturable and probably carrier mediated followed by a slower phase that is apparently passive.

EXCRETION

The feces are the major route of excretion for zinc 
(Hambidge et al, 1986). A healthy adult who consumes 12-15 $\mathrm{mg}$ of zinc per day and is in zinc balance will excrete approximately $90 \%$ of this ingested zinc in the feces. Endogenous zinc can amount to 1-2 $\mathrm{mg}$ per day (Prasad, 1982) with a major contributor being pancreatic secretions (Hambidge et al., 1986). Urinary zinc loss is approximately $0.5 \mathrm{mg}$ per day but can vary with the level of dietary intake (Prasad, 1982). It arises from the ultrafilterable portion of plasma zinc. Sweat is another route of zinc excretion and approximately $0.5 \mathrm{mg}$ may be lost daily. This zinc loss can increase considerably under conditions of profuse sweating.

\section{METABOLIBM}

The most widely known function of zinc is its involvement in enzyme function and structure (Hambidge et al., 1986; Prasad, 1982). Carbonic anhydrase was the first zinc metalloenzyme to be isolated and purified. Over $200 \mathrm{zinc}$ enzymes or other proteins have been identified from various sources (Hambidge et al., 1986). Consequently, zinc plays an important role in the metabolisms of proteins, carbohydrates, lipids, and nucleic acids. other zinc-containing enzymes include alkaline phosphatase, alcohol dehydrogenase, superoxide dismutase, carboxypeptidase, and RNA polymerase.

zinc, both alone and as a metalloenzyme, plays a role in many functions in the body (Prasad, 1982; Hambidge et al., 1986). As an ionic species, zinc stabilizes biomembrane structures and polynucleotide conformation (Bettger and 
O'Dell, 1981). The involvement of $z$ inc in nucleic acid and protein metabolism makes it important for cell differentiation and replication (Prasad, 1982; Hambidge et al., 1986). Zinc participates in the production, storage, and secretion of hormones as well as in the effectiveness of receptor sites and end organs. In particular, zinc deficiency adversely affects testicular function and appears to be essential for spermatogenesis and testosterone synthesis. Zinc is important for the growth of both the skeleton and body tissues of young animals, including man, with growth retardation being one of the first signs of zinc deficiency. Recovery from malnutrition appears to be optimized with the addition of zinc to the diet (Golden and Golden, 1981). Zinc appears to be required for appetite and normal taste perception. Zinc is essential to the integrity of the immune system (Prasad, 1982; Hambidge et al., 1986). The predominant influence is on $T$ cell functions but other reported functions include thymic hormone production and activity, lymphocyte function, natural killer cell function, antibody-dependent cell-mediated cytotoxicity, immunological ontogeny, neutrophil function, and lymphokine production. zinc is required for keratogenesis and normal integrity of the skin and it may also play a role in wound healing (Hambidge et al,, 1986). Zinc is essential for normal sexual development of males and normal reproduction, from estrus to lactation, in females. The retina-choroid complex has the highest zinc concentration with zinc being 
involved in several processes related to vision.

\section{BIHC DEFICIENCY IN THE RAT}

The NRC (1978) zinc requirement for the rat maintained in a zinc-free environment and fed a casein or egg white diet is $12 \mathrm{mg} / \mathrm{kg}$ for maximum weight gain. A severe deficiency will result with a diet containing less than $1 \mathrm{ppm}(1 \mathrm{mg} / \mathrm{kg})$ of zinc with deficiency signs occurring rapidly.

Reduced growth rate and feed intake are the first effects of $z$ inc deficiency in the growing rat (Swenerton and Hurley, 1968; Williams and Mills, 1970). As the deficiency progresses, alopecia, loss of the hair follicles, and dermal lesions occur (Swenerton and Hurley, 1968). The lesions involve thickening or hyperkeratinization of the epit. $\geq 1$ ial cells and can also occur in the esophagus. Some deficient rats maintain the immature hair of the weanling. At the height of the deficiency state, the rat is extremely emaciated with an abnormal "kangaroo-like" posture. When less than $2 \mathrm{mg} / \mathrm{kg}$ of zinc is fed to females, a severe disruption of the estrus cycle occurs, and in most cases no mating with normal males occurs (Hurley and Swenerton, 1966). A dietary concentration of less than $0.5 \mathrm{mg} / \mathrm{kg}$ zinc fed to growing male rats arrested spermatogenesis, resulted in atrophy of the germinal epithelial, and reduced growth of the pituitary and accessory sex organs. Teratogenic effects can include hydrocephaly and other central nervous system malformations, cleft palate, 
fused or missing digits, and urogenital abnormalities. Dietary intakes of zinc are reflected in the zinc concentrations of some tissues (e.g., blood, hair, bone, testes, liver) but others (e.g., brain, lung, muscle, heart) are insensitive to marked reductions or increases in zinc intake (Hambidge et al., 1986).

Rats given a zinc deficient diet will voluntarily restrict their food intake (Chesters and Quarterman, 1970; Chesters and will, 1973). Day-to-day food intake varies and a cyclical pattern of eating develops (Chesters and Quarterman, 1970; williams and Mills, 1970). This appears to be a necessary adaptation since force-feeding of zinc-depleted rats with 1408 of their voluntary intake rapidly causes signs of ill health (Chesters and Quarterman, 1970). The reasoning behind the anorexia remains uncertain. It may be the result of a $z$ incprotein interaction since $z$ inc deficient rats will selectively choose a diet with the lower protein content (Chester and Will, 1973; Reeves and O'Dell, 1981). Decreased food intake may also be an adaptation to limit growth so the available zinc is used for more essential functions. Altered taste perception may also be involved. As a result, it becomes difficult to separate the effects due to lowered food intake with those of decreased zinc intake. To overcome this problem, pair feeding is usually included for control of food intake. However, this is not a "perfect" control since pairfed animals develop a meal-eating pattern while the zinc- 
deficient animals remain nibblers (Chesters and Quarterman, 1970; Wallwork et al., 1981). This altering of the frequency of food ingestion may result in differences in nutrient metabolism and body composition (Fabry and Braun, 1967; Leveille, 1972).

\section{ZINC DEPICIENCY IN HUWNB}

zinc deficiency can be thought of as a continuum with mild or marginal deficiency on the left and severe deficiency on the right (Prasad, 1988). A severe zinc deficiency is the result of unusual circumstances such as a zinc-free parenteral feeding or the result of a genetic disorder of zinc metabolism such as acrodermatitis enteropathica. The clinical features are easily recognizable: neuropsychiatric changes, dermal lesions, diarrhea, and alopecia (Aggett, 1989). A mild or marginal deficiency is more difficult to diagnose because there is no clinical feature which is unique to it. Possible ones are slowing of physical growth, poor appetite and diminished taste acuity, and depressed immune status. Growth is the outcome variable frequently measured. There is no reliable, sensitive laboratory index of zinc status (Solomons, 1979). Randomized and controlled trials of zinc supplementation are considered to be the most reliable way of confirming the existence of mild zinc deficiency and for assessing its effects on clinical status (Walravens et al,, 1983).

It was originally belleved that $z$ inc deficiency could not 
occur in man. This view has now changed. In the early 1960's, Prasad and coworkers (1963) described a syndrome of "nutritional dwarfism" in Egypt. Clinical features included growth retardation, hypogonadism in males, rough and dry skin, anemia responsive to iron, enlarged liver and spleen, mental lethargy, and susceptibility to infections. Mild zinc deficiency was confirmed from blood $z$ inc values and radiolabelled tracer studies.

other work followed this report from Egypt. Carter et al. (1969) completed a zinc supplementation trial in Cairo but did not confirm an effect of zinc on growth. Studies in Iran gave both positive (Halsted et al., 1972; Ronaghy est al., 1974) and negative results (Mahloudji et al., 1975; Ronaghy et al., 1969). However, not all of the studies were "double-blind" or random and there was lack of good dietary information. It is unlikely that zinc deficiency was the only contributing factor. Coble et al. (1971) studied endocrine function in boys from the Nile valley with retarded growth and delayed sexual maturation and concluded that it was not possible to attribute the delayed development of the boys solely to zinc deficiency. Other conditions associated with growth retardation and delayed puberty were also present in the region a population of low socioeconomic status, poor hygiene, high incidence of infectious disease, poor protein and calorie nutrition, and other mineral deficiencies. Golden and Golden $(1979 ; 1981)$ have documented the occurrence of zinc deficiency 
with protein energy malnutrition in children.

zinc deficiency has been investigated in other areas throughout the world including Colorado (Hambidge et ale, 1972; Walravens and Hambidge, 1976; Walravens et aㅛ., 1983), southern Ontario (Smit Vanderkooy and Gibson, 1987; Gibson ett al., 1989), China (Chen et al., 1985), Yugoslavia (Buzina et al., 1980), and Australia (Cheek et al., 1982). From the results of these studies, many investigators concluded that zinc deficiency, especially a mild or marginal one, is prevalent.

Hambidge et al. (1972) found low levels of hair zinc associated with anorexia, poor growth, and hypogeusia in young children from Denver which the authors attributed to zinc deficiency. Similar findings were more recently reported in Yugoslavia (Buzina et al., 1980) and China (Chen et al., 1985). Children in both of these groups were also in a poor nutritional status. Smit Vanderkooy and Gibson (1987) found preschool males with low hair zinc $(<70 \mu \mathrm{g} / \mathrm{g})$ had a lower mean height-for-age percentile. They suggested a mild zinc deficiency since these children had lower dietary intakes of readily available $z$ inc.

Walravens and Hambidge (1976) demonstrated that $z$ inc supplemented male infants were $2.1 \mathrm{~cm}$ greater in length $(p<0.025)$ and $535 \mathrm{~g}$ greater in weight $(p<0.05)$ than controls. Male preschool children who were supplemented had a 108 greater height velocity $(p<0.001)$ than controls (Walravens et ale, 
1983). No effect was demonstrated in middle-income children consuming $z$ inc-fortified breakfast cereals (Hambidge et al., 1979). Subjects in this study were not selected on the basis of height or zinc status; therefore, they were probably not zinc deficient. zinc does not have any pharmacological effects on growth or other functional measures of $z$ inc status. In a double-blind, pair-matched study, boys with a hair zinc less than $1.68 \mu \mathrm{mol} / \mathrm{g}$ responded to the zinc supplement with a higher mean change in height-for-age $z$ scores $(p<0.05)$; taste acuity, energy intakes, and attention span were unaffected (Gibson et al., 1989). In contrast, Krebs et al. (1984) reported significant improvements in children's appetite and food intake when zinc supplemented. Immune function was also reported to respond to $z$ inc supplementation (Castillo-Duran et al., 1987).

\section{THE BOKATOMEDIN HYPOTHE8I8 AND GRONTH}

\section{GROWTH HORMONE}

Growth hormone (GH) is an anabolic hormone synthesized by the somatotropes of the anterior pituitary and is under hypothalamic control (Granner, 1990). It is a single polypeptide with an approximate molecular weight of 22,000 in mammalian species. Human $G H(h G H)$ contains 191 amino acid residues. Although there is a high degree of sequence homology among various mammalian growth hormones, only hGH or that of other higher primates is active in humans. In the 
rat, hGH is effective but antibodies will be produced after 14 days (A. Skottner, pers. comm.). Growth hormone is essential for postnatal growth and for normal carbohydrate, lipid, nitrogen, and mineral metabolism (Granner, 1990).

The action of $\mathrm{GH}$ on bone includes promoting growth of long bones at the epiphyseal plates in growing children and appositional or acral growth in adults and increasing cartilage formation in children (Granner, 1990). The "somatomedin hypothesis" states that the growth-promoting effects of GH are primarily mediated through the action of insulin-like growth factor I (IGF-I) (Salmon and Daughaday, 1957; Elders et al., 1975).

\section{INSULIN-LIKE GRONTH FACTORB}

Insulin-like growth factors are single-chain polypeptides of approximately $7.5 \mathrm{kD}$ which occur in blood and most tissues of the body (Humbel, 1990). The two circulating forms are IGF-I, also known as somatomedin-C $(\mathrm{Sm}-\mathrm{C})$, and IGF-II. The peptides consist of four peptide domains, A, B, C, and D (Clemmons, 1989). IGF-I and IGF-II share $43 \%$ and $41 \%$ sequence homology with proinsulin respectively (Zapf and Froesch, 1986). The amino acid sequence of IGF-I for six species (human, bovine, porcine, ovine, rat, and mouse) has been determined. IGF-I in all six species consists of 70 amino acid residues while IGF-II has 67 residues (Humbel, 1990). There is a $62 \%$ sequence homology between the two growth factors. 
Normal serum and plasma concentrations of IGF-I and IGF-II in adult man are 200 and $700 \mathrm{ng} / \mathrm{ml}$ respectively (Daughaday and Rotwein, 1989). Prior to puberty, IGF-I reaches adult levels and then rises 2-3 fold during puberty. IGF-II does not change significantly. Hypopituitary dwarfs, or persons with untreated GH deficiency, have reduced concentrations of IGF-I and IGF-II, $10 \mathrm{ng} / \mathrm{ml}$ and $200 \mathrm{ng} / \mathrm{ml}$ respectively (Zapf and Froesch, 1986). Comparisons of growth rates between normal and GH-deficient children suggest that IGF-I increases growth in later childhood and that it is particularly responsible for the pubertal growth spurt (Cara et al, 1987). Conversely, patients with GH-secreting hormones, ie gigantism or acromegaly, show increased concentrations of IGF-I (600-1000 $\mathrm{ng} / \mathrm{ml}$ ) but normal or subnormal levels of IGF-II (zapf and Froesch, 1986; Granner, 1990).

Insulin-like growth factor I and IGF-II show both in vitro and in vivo insulin-like metabolic effects, such as on glucose transport and on blood glucose, but only at relatively high concentrations (Phillips and Unterman, 1984; Humbel, 1990). The binding of IGF-I to binding proteins in plasma probably prevents hypoglycemia under physiological conditions (Humbel, 1990). The biologically relevant effects of IGF-I at nanomolar concentrations are the stimulation of cell proliferation and, in certain tissues, cell differentiation. In vitro, IGF-II mimicks the effects of IGF-I. While some investigators consider IGF-II to be a fetal growth factor in 
the rat, this view has not been supported for man. Therefore, the biological role of IGF-II has yet to be defined and its biological relevance is under dispute.

\section{THE BOXNTOMEDIN RYPOTHBI8}

The liver is the most important source of circulating IGF-I with the major regulator being GH (Daughaday 1989; Humbel, 1990). Hypophysectomy reduces the level of IGF-I in the liver while GH treatment of hypophysectomized rats restores circulating levels (Schwander ett al,, 1983). Accordingly, GH releasing hormone is secreted into the portal venous system which connects directly to the anterior pituitary gland and stimulates the secretion of GH (Elders et ald, 1975). According to the somatomedin hypothesis, GH then acts on the liver to stimulate the secretion of IGF-I which is transported via the plasma to the cartilage where a number of anabolic events are initiated. These include the stimulation of mitotic activity, deoxyribonucleic acid (DNA) synthesis, DNAdependent ribonucleic acid (RNA) synthesis, protein synthesis, biosynthesis of glycosaminoglycans (GAGS), collagen synthesis, and increased thickness of the epiphyseal growth plate with resultant long bone growth. If the somatomedin hypothesis is true, IGF-I would act as an endocrine growth factor with circulating IGF-I being the major source for skeletal growth (Elders et al., 1975; Daughaday, 1989; Humbel, 1990).

Before the availability of a radioimmunoassay for measuring IGF-I specifically, the bioassay for IGF-I measured somato- 
medin activity or sulfate incorporation into cartilage glycosaminoglycans (Elders et al., 1975). The biosynthesis of chondroitin sulfate, a major GAG found in cartilage, begins with the transfer of xylose from UDP-xylose to the serine residue of the receptor protein. Galactose and glucuronic acid are then added sequentially to form a polysaccharide chain. Sulfation occurs simultaneously with the polymerization of the polysaccharide chain. An alteration in any step of the biosynthesis will decrease sulfate uptake.

Circulating IGF-I is believed to act in a negative feedback system to inhibit the release of $\mathrm{GH}$ (Phillips and Unterman, 1984; Humbel, 1990). In a pituitary cell culture system, IGFI inhibited the $\mathrm{GH}$ release stimulated by a synthetic $\mathrm{GH}$ releasing factor (Humbel, 1990). Therefore, IGF-I can selfregulate itself. Insulin and adequate protein and energy are important to maintain normal circulating levels while excess steroids, protein energy malnutrition, and certain illnesses adversely affect the activity of IGF-I (Figure 1.1) (Phillips and Unterman, 1984).

Lack of purified IGF-I made it difficult to study the in vivo action of IGF-I. Growth hormone improved growth and increased IGF-I when administered to hypophysectomized rats (Kemp et al ., 1981). Early reports demonstrated that plasma peptide fractions containing somatomedin activity caused an increase in body weight and sulfate-incorporating activity of cartilage in snell dwarf mice when administered subcuraneously 


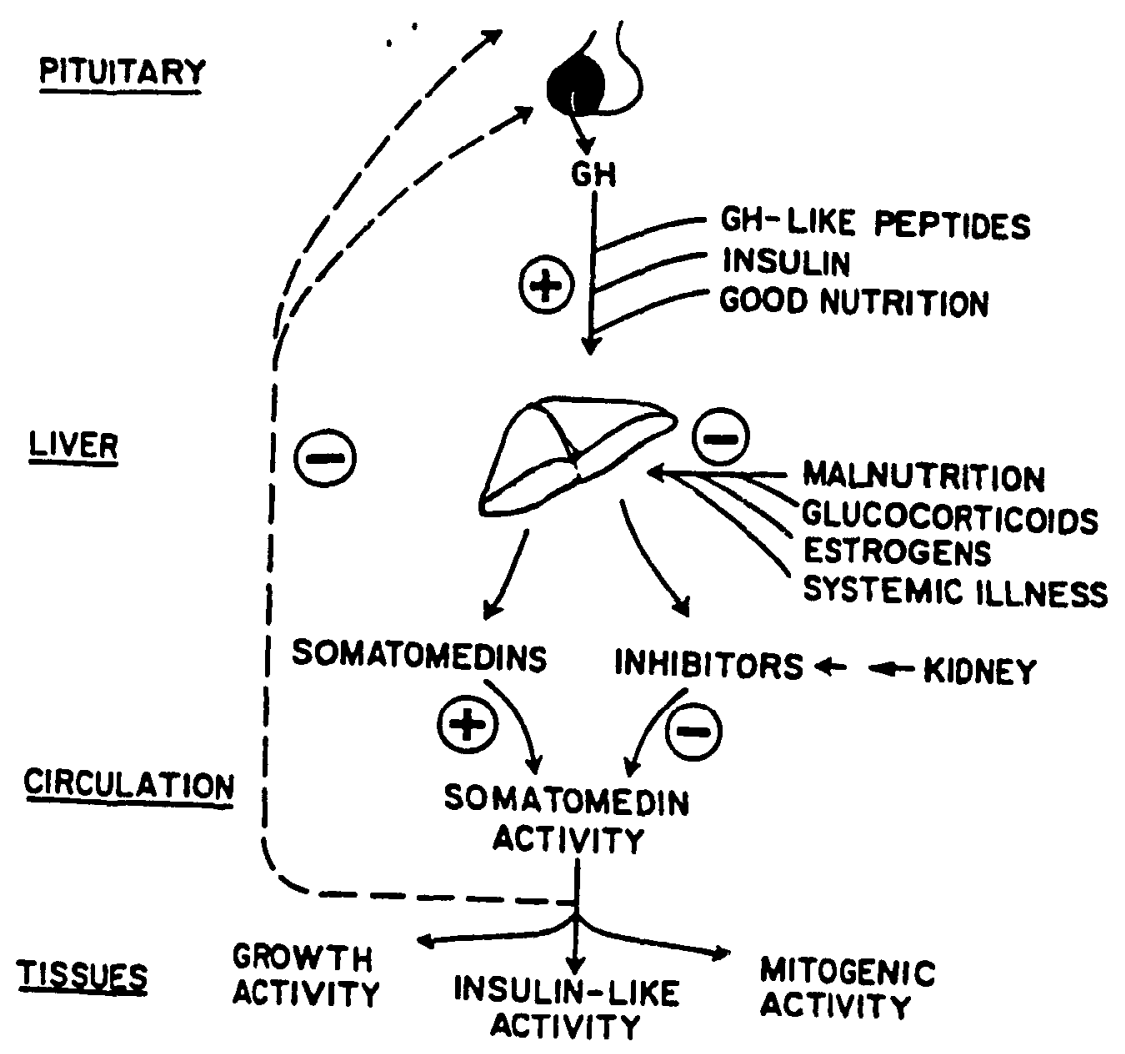

Fjgure 1.1 Regulation of somatomedin (IGF-I)

(from Phillips and Unterman, 1984) 
three times per day for 2-4 weeks (van Buul-offers and van den Brande, 1979; Holder et al., 1981). However, growth responses were always smaller than those induced by $\mathrm{GH}$. Schoenle et al. (1982) demonstrated small increases in tibial epiphyseal width, 3H-thymidine incorporation into costal cartilage DNA, and body weight compared to controls. The increases were similar to those obtained with hGH suggesting that IGF-I was capable of mimicking the effects of $\mathrm{GH}$. These results were assumed to be direct support of the somatomedin hypothesis with IGF-I acting in a endocrine manner.

However, Skottner et al. (1987) found that recombinant human IGF-I (hIGF-I), whether given by subcutaneous infusion, twice daily injections, or continuous intravenous infusion, had a very small effect on growth parameters in hypophysectomized rats compared to $\mathrm{GH}$. Even when given in combination with GH, hIGF-I had little effect, particularly on skeletal growth, which raised the question of the importance of circulating IGF-I as an endocrine mediator of the growthpromoting actions of $\mathrm{GH}$. However, hypophysectomized rats may not be the most appropriate model since they lack other pituitary hormones besides $\mathrm{GH}$, and some of these can influence growth in hypophysectomized animals. In a mutant dwarf rat with isolated GH deficiency, both hGH and hIGF-I significantly increased body weight but hIGF-I resulted in a significantly smaller stimulation of bone growth (Skottner et al., 1989). The pattern of growth produced also differed with hGH 
resulting in proportional growth while hIGF-I increased the size of the kidneys, adrenal, and spleen. It was concluded that GH and IGF-I differed quantitatively and qualitatively in their pattern of action and IGF-I was not acting as a simple mediator of $\mathrm{GH}$. In neonatal rats, however, IGF-I but not GH showed an effect on somatic and organ growth (Philipps et ale, 1988). Embryonic and neonatal growth is not believed to be GH-dependent.

Investigators have also administ red $\mathrm{GH}$ and IGF-I locally into the tibiae of rats using daily injections or arterial infusion. The contralateral tibia serves as an internal control. When injected into the tibial epiphyseal plate of hypophysectomized rats, both rat $\mathrm{GH}$ ( $\mathrm{rGH}$ ), hGH, and hIGF-I caused unilateral tibial growth (Russell and Spencer, 1985). Isgaard et al. (1986) also stimulated local bone growth using GH from various species. The effect for IGF-I was smaller than that of $\mathrm{GH}$. When infused into the arterial supply of the hindlimb, $r G H$ and hIGF-I stimulated growth of the epiphyseal plate of the infused limb but not of the noninfused leg (Schlechter et al., 1986a). IGF-I showed a dose related response. An IGF-I antibody completely abolished the effect of rGH when it was co-infused with the hormone. High doses of either $\mathrm{rGH}$ or hGH resulted in a systemic effect with epiphyseal growth occurring in the noninfused leg (Schlechter et al., 1986b; Nilsson et al., 1987). Therefore, it was concluded that $\mathrm{GH}$ in vivo directly stimulates epiphyseal car- 
tilage growth through stimulating the local production of IGFI which then acts in a paracrine or autocrine manner. Some researchers questioned the need for circulating IGF-I.

Growth hormone significantly enhances the increase of IGF-I in a culture of embryonal rat tibiae (Stracke et al., 1984). Growth hormone will restore the number of IGF-I mRNA copies in the rib growth plate of hypophysectomized rats which further supports the paracrine/autocrine hypothesis (Isgaard et al., 1988). However, these results do not exclude the possibility that circulating IGF-I may be involved in the growth process. It also appears that IGF-I mediates the growth-promoting effect of $\mathrm{GH}$ and not GH's action on bone resorption (Spencer et al., 1991).

Longitudinal bone growth results from the production of new cells in the growth plate and from the expansion of these cells as they are displaced into the maturation zone by continuing cell division (Isaksson et al., 1987; Robertson, 1990). The growth plate consists of several cell layers: the germinal or reserve cell layer, the proliferative cell layer, the hypertrophic cell layer, and the calcification layer.

In support of the need for circulating IGF-I, early investigators failed to show any stimulatory effect of $\mathrm{GH}$ on cell proliferation in vitro (Ash and Francis, 1975; Ashton and Francis, 1977; 1978). However, Madsen et al. (1983) found that hGH did stimulate DNA synthesis in chondrocytes isolated from rabbit ears and rat rib growth plates. When iooking at 
the distribution of IGF-I in the growth plate, cells in the proliferative zone contained more IGF-I (Nilsson et ale, 1986). It was also found that the gene for IGF-I was being expressed in chondrocytes from the proliferative and hypertrophic zones (Nilsson et al,, 1990). Hypophysectomy decreased the expression of IGF-I which could be restored with GH. It appeared that $\mathrm{GH}$ regulated the synthesis of IGF-I in the growth plate which further supported the paracrine/autocrine hypothesis.

Human GH and hIGF-I was added to cultures of rat epiphyseal chondrocytes and the resultant colony size and number examined (Lindahl et al., 1987a). Both hGH and hIGF-I induced colony formation; however, hGH potentiated the formation of large size colonies while hIGF-I resulted in a higher proportion of small size chondrocyte colonies. Lindahl et al. (1987b) then looked at colony formation of chondrocytes isolated at different layers of the growth plate, corresponding to different stages of maturation. Human IGF-I increased the number of colonies in chondrocytes isolated from the proximal and intermediate zones. Low concentrations of hGH (10-40 $\mathrm{ng} / \mathrm{ml})$ stimulated colony formation in chondrocytes from the proximal zone whereas higher concentrations were ineffective. Again, hIGF-I potentiated small size colonies while hGH increased the number of large size colonies in the proximal zone. The distal zone showed no significant response to either hGH or hIGF-I. It was concluded that GH is capable of 
interacting with a limited number of cells which exhibit a high proliferative capacity (Lindahl et al., 1987a; 1987b). Pretreating hypophysectomized rats with hGH increased the responsiveness of cultured epiphyseal chondrocytes to the growth-promoting effect of subsequently added hIGF-I (Lindahl et ale, 1987C).

Based on the above work, Isaksson and coworkers (1987; 1990) suggested that $G H$ directly stimulates the differentiation of prechondrocytes or young differentiating cells. During the process of cell differentiation, cells, directly stimulated by $\mathrm{GH}$, become responsive to IGF-I. Concomitantly, the gene encoding for IGF-I is expressed, which results in an increased. synthesis of IGF-I in the differentiating cells. The locally produced IGF-I is externalized and subsequently interacts with receptors on the proliferating chondrocytes by autocrine or paracrine mechanism(s). Circulating IGF-I is of limited value in the growth process.

Daughaday (1989) put forth several arguments concerning the importance of circulating IGF-I in skeletal growth. They are as follows: (1) The plasma concentration of IGF-I is much higher than that of any other tissue; (2) Plasma IGF-I is biologically active. Normal rat serum stimulates anabolic processes in isolated cartilage segments; (3) The ability of mesenchymal and skeletal tissues to synthesize IGF-I is much less than that of the liver. The concentration of IGF-I MRNA in rat costal growth plate after $\mathrm{GH}$ treatment is only 4-6\% of 
that in liver; (4) The in vitro addition of $\mathrm{GH}$ stimulates anabolic processes and DNA synthesis to a much smaller degree than does IGF-I in all experiments with cartilage and bone tissue; and (5) The in vivo actions of $\mathrm{GH}$ on cartilage establish the local production and action of IGF-I but they do not establish that autocrine/paracrine actions of IGF-I are sufficient to explain normal growth. Systemic injections of GH achieve a greater growth response than do local injections into the growth plate.

Daughaday (1989) statistically analyzed the data from several studies to predict the growth response to local and systemic $\mathrm{GH}$ injections. Using a regression line calculated from Thorngren and Hansson (1974) as comparison, Daughaday (1989) showed that the results obtained by Isgaard et ale (1986) with local injections of $0.5 \mu \mathrm{g}$ hGH per day only accounted for $12 \%$ of the longitudinal growth response that could have been induced by subcutaneous $\mathrm{GH}$. A near maximal response is achieved with $400 \mathrm{\mu g}$ of $\mathrm{hGH}$ subcutaneously (Daughaday, 1989). The response was equivalent to that predicted for a daily dose of $14 \mu \mathrm{g}$ given subcutaneously. Analysis of data from Russell and Spencer (1985) demonstrated that the injection of $\mathrm{rGH}$ at $5 \mu \mathrm{g}$ per day into the tibial growth plate for 4 days achieved only $22 \%$ of the increase in width as predicted for $400 \mu \mathrm{g}$ of $\mathrm{GH}$ subcutaneously (Daughaday, 1989). The regression line was based on work from Geschwind and Li. Scheven and Hamiiton (1991) studied longitudinal bone 
growth using an in vitre model system of intact rat long bones. Growth arrest occurred in neonatal metatarsals after 1-2 days in a serum-free medium. Since they were able to respond to exogenously added IGF-I and $G H$, the authors suggested that endogenous factors were not sufficient to promote growth. Systemic, blood-borne, factors are probably required for in vivo regulation of long bone growth.

Daughaday (1989) concluded that "hormonal somatomedins reaching skeletal tissues from the circulating plasma have a major, if not predominant, role in the regulation of skeletal growth". Humbel (1990) proposed the following modifications to the original hypothesis: the growth promoting activity of GH is due, on the one hand, to direct effects on the periphery enabling cells to produce and to respond to IGF-I and, on the other hand, to indirect effects, mostly on liver, to increase serum concentrations of IGF-I. This is illustrated in Figure 1.2. IGF-I can mimic most, but not all, effects of $\mathrm{GH}$. The relative contributions of circulating IGF-I, locally produced IGF-I, and direct action of $G H$ are at present disputed (Daughaday, 1989; Humbel, 1990).

\section{NOTRITIONAI REGULATION OF IGF-I}

Nutrition, specifically protein and energy, appear to play a role in the regulation of IGF-I. Grant et al. (1973) observed that serum somatomedins bioactivity was low in children with protein-calorie malnutrition, despite high $\mathbf{G H}$ 


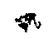

a

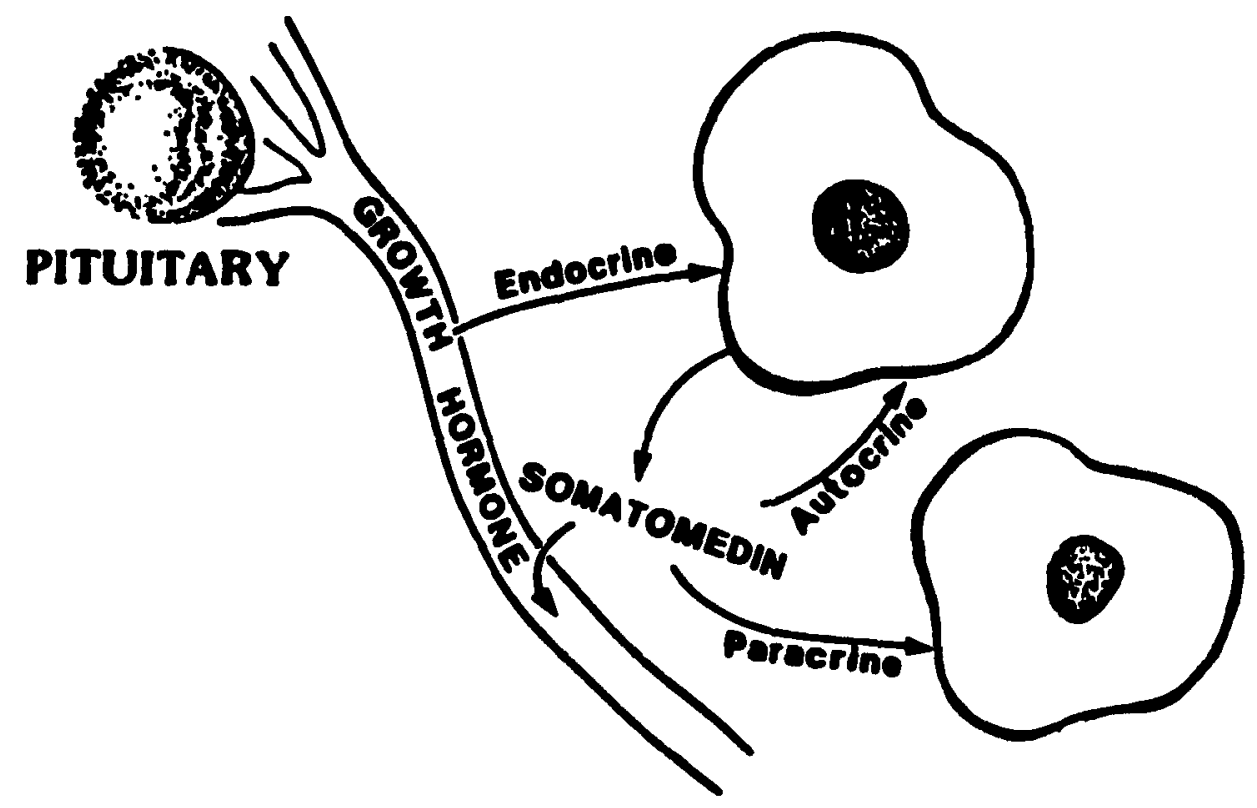

Figure 1.2 Activities of somatomedins (IGF-I) (from Clemmons and Underwood, 1991) 
levels. Merimee et als (1982) later showed that after three days of fasting, normal subjects showed no change in serum IGF-I in response to $\mathrm{GH}$ injections. In fasted rats as well, bGH is not able to prevent the fall in serum somatomedin activity (Phillips and Young, 1976). Refeeding returns somatomedin levels and cartilage growth activity to control values. Prewitt et al. (1982) found that serum Sm-C was influenced by both protein and energy intake, although protein appeared to be the most important variable. Reeves et al. (1979) observed an inverse relationship between dietary fat and plasma somatomedin activity.

The effect of fasting on IGF-I may be regulated through a reduction of $\mathrm{GH}$ receptors in the liver. When rats are fasted for three days, they experience marked reductions in serum IGF-I and in binding of $\mathrm{GH}$ to its hepatic receptor (Maes et ale, 1983). During refeeding, hepatic GH binding increased at approximately the same rate as the serum IGF-I concentrations. Furthermore, the decrease in $\mathrm{GH}$ receptors that occurs during fasting is accompanied by a parallel decrease in hepatic $\mathbf{G H}$ receptor mRNA abundance (Straus and Takemoto, 1990). Steadystate hepatic IGF-I mRNA levels also decrease in fasted rats compared to controls indicating an effect on transcription of IGF-I MRNA (Emler and Schalch, 1987). Refeeding produces a prompt increase in steadystate mRNA levels (Straus and Takemoto, 1990).

Dietary protein restriction appears to lower serum IGF-I 
through a different mechanism. While serum IGF-I is consistently reduced in rats subject to protein restriction, only modest reductions in GH binding occur (Maes et ale, 1984a). Also, the serum IGF-I response to exogenous $G H$ is attenuated in protein deficient rats (Maes et als, 1988). Protein restriction appears to cause post-receptor resistance to the action of $\mathrm{GH}$, and the low IGF-I is not mediated via reduced GH binding (Maiter et al., 1988). Protein restriction also decreases hepatic IGF-I MRNA commensurate with the decline in serum IGF-I (Moats-Staats et al, 1984). It also appears that protein restriction may cause resistance to IGF-I since infusion of IGF-I into rats fed $5 \%$ protein diets does not restore the normal rate of increase in tail length, weight, or tibial epiphyseal width despite normalization of serum IGF-I (Thissen et al., 1991). The effect of protein deprivation appears to be age-dependent, since it is less profound in older animals (Fliesen et al., 1989). These effects of energy and protein on IGF-I are illustrated in Figure 1.3.

The response of circulating IGF-I to dietary protein and/or energy restriction has also been explored in humans. Fasting causes reductions in plasma IGF-I which return to normal with refeeding (Isley et al., 1983; 1984). Restricting protein and/or energy in the refeeding diet causes smaller increases in circulating IGF-I compared to the control diet. In malnourished hospital patients, IGF-I appears to respond more quickly to nutritional interventions compared to conventional 


\section{NUTRITIONAL REGUULATION OF THE GH/IGF-1/IGF BINDING PROTEIN CASCADE}

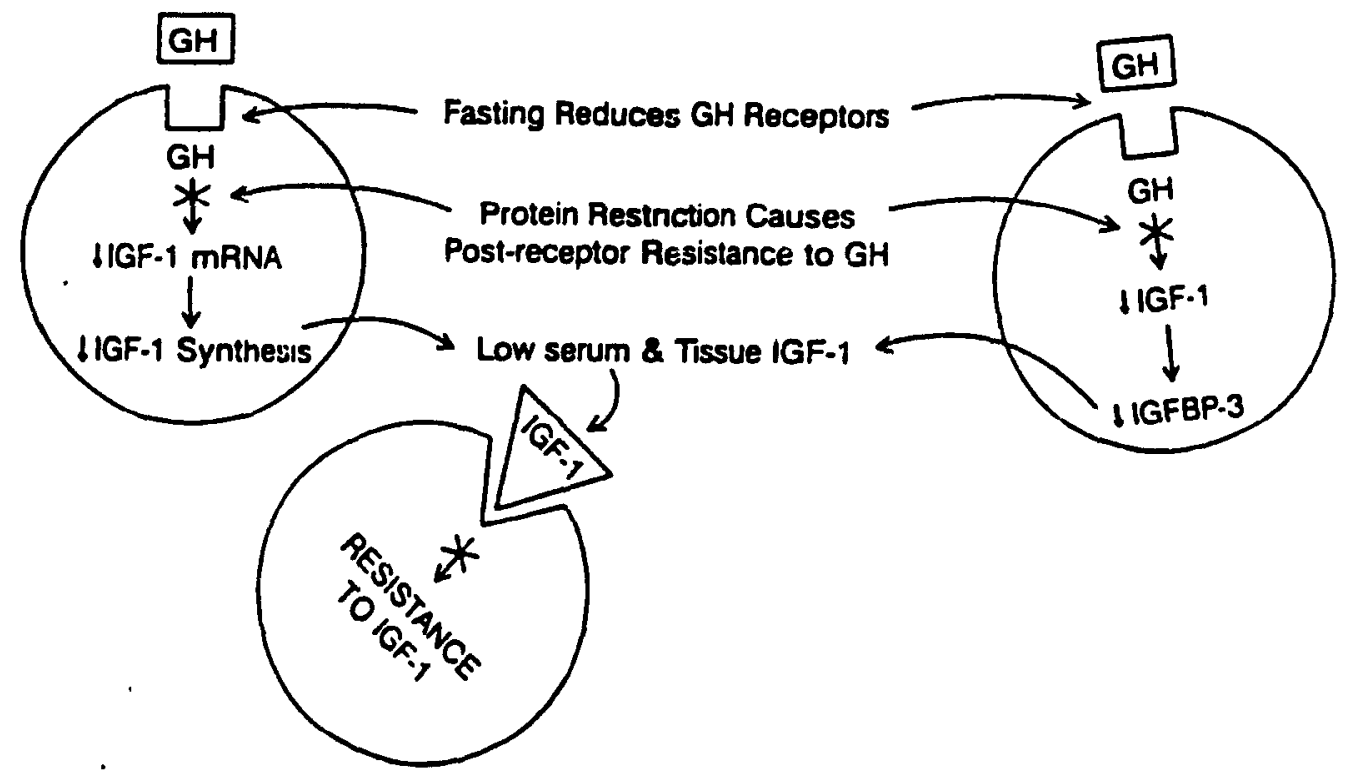

Figure 1.3 (from Clemmons and Underhill, 1991) 
indices of nutritional status, such as albumin, prealbumin, transferrin, and retinol binding protein (clemmons et ale, 1985; Donahue and Phillips, 1989). Thus, it may be a useful tool for monitoring short-term changes in nutritional status.

\section{IXC, GROWTH HORYONE, ND IGY-I}

Several mechanisms have been proposed to explain the growth retardation seen with zinc deficiency. These include: altered activities of zinc enzymes adversely affecting nucleic acid metabolism, protein synthesis, and cell division; decreased immune function leading to increased infection and stress on the individual; and (3) decreased taste acuity and appetite resulting in decreased food intake. A fourth possible mechanism is an adverse effect on the generation of IGF-I which would alter cartilage metabolism (Cossack, 1984; 1986; Bolze et al., 1987).

Oner and Bor (1978) observed a marked reduction in serum somatomedin A (later found to be IGF-I) activity in zinc deficient rats compared to controls. However, the authors failed to use a pair-fed group so it is difficult to attribute the fall in somatomedin A activity entirely to a lack of $z$ inc. Cossack (1984) demonstrated that both decreased zinc and decreased food intake contribute to the fall in sm-c. zinc deficient rats had significantly depressed growth (as measured by body weight gain) and plasma $s m-C$ compared to both pair-fed groups and the ad libitum control group. As well, values for 
the pair-fed groups were also significantly lower than the ad libitum controls indicating an effect of decreased food intake alone. It was also observed that plasma $\mathrm{Sm}-\mathrm{C}$ correlated with tibial zinc concentrations $(r=0.79, p<0.005)$ and with body weight gain $(r=0.96, p<0.001)$. Cossack (1986) further established the importance of $z$ inc for maintaining normal $\mathrm{sm}-\mathrm{C}$ levels. Growing rats were given one of six test diets based on combinations of two levels of protein and three levels of zinc. All rats were given the same amount of diet consumed by the low-zinc-low-protein group. An additional control group was given the medium-zinc-high-protein diet ad libitum. In rats given the low-zinc-low-protein, the level of plasma Sm-C increased as the amount of zinc or zinc and protein increased in the diet. However, no change was observed when the level of protein ajone was increased. Among all groups tested, the ad libitum fed rats showed the highest level of plasma Sm-C. Rats fasted for three days showed an immediate decrease in SmC (Cossack, 1988). Again, adequate zinc was required in the refeeding diet to ensure that plasma $\mathrm{Sm-C}$ returned to normal. The zinc deficient and $30 \mathrm{ppm} z$ inc groups experienced transient increases in $\mathrm{sm}-\mathrm{C}$ followed by further declines. The transient increase was attributed to food intake and not food composition.

Bolze et al. (1987) investigated the influence of zinc on growth, somatomedin activity, and glycosaminoglycan metabolism in the rat. Weanling male rats were fed control ad libitum, 
zinc deficient ( $1 \mathrm{ppm} z$ inc), or pair-fed control diets for 13 days. Rats were then refed the control diets for up to eight days and serially killed. Bioassayable somatomedin activity was $0.81,0.42$, and $0.33 \pm 0.09$ relative activity for ad libitum, pair-fed and zinc deficient rats at the end of depletion. Radiolabelled sulfate uptake by glycosaminoglycans (GAG) was significantly less in the zinc deficient rats compared to either ad libitum or pair-fed groups. Xylosyltransferase activity, an enzyme involved in GAG synthesis, was also significantly depressed in the zinc deficient group compared to the other two groups. Somatomedin activity and GAG metabolism returned to normal after refeeding for 2-5 days in the pair-fed and for 5-8 days in the zinc deficient rats again suggesting separate effects of food intake and zinc on somatomedin and cartilage activity. This study by Bolze et al. (1987) was important since. it demonstrated an effect of zinc on the specific activity of IGF-I whereas others were investigating circulating levels and growth only.

Since GH is considered the major regulator of IGF-I, the effect of zinc on IGF-I may be mediated through GH. Root et al. (1979) demonstrated that zinc deficiency decreased serum and pituitary levels of $\mathrm{GH}$ in both sexually mature and immature rats. Body weight and tail lengths were concomitantly reduced. In $\mathrm{GH}$ deficient children, $\mathrm{GH}$ treatment significantly increased hair zinc concentrations and decreased 
urinary zinc excretion suggesting a role for $G H$ in zinc metabolism in children (Cheruvanky et al., 1982). The addition of $50 \mathrm{mg} /$ day of zinc to some of the children taking GH increased their rate of growth to $7.3 \pm 2.5$ from $5.2 \pm 2.5$ of the previous year. Ghavami-Maibodi et al. (1983) supplemented healthy short children who had low hair zinc concentrations with oral zinc supplements for one year. Children with other reasons for growth retardation were excluded. There was a significant increase in growth rates for the children whose hair zinc concentrations increased. Growth hormone and $\mathrm{Sm}-\mathrm{C}$ also significantly increased after the zinc supplement. Collipp et al. (1982) and Nishi et al. (1989) both reported cases of poor growth and GH deficiency apparently due to zinc deficiency.

From these studies, some investigators concluded that the effect of zinc on growth may, in part, be mediated through its effect on $\mathrm{GH}$ levels. It is also possible that $\mathrm{GH}$ treatment increases the requirement for zinc because of the deposition on new tissue. Richards and Marshall (1983) supplemented GH treatment with zinc and found no effect on growth or serum and hair zinc compared to nonsupplemented controls. The authors concluded that $\mathrm{GH}$ does not alter zinc requirements and zinc does not improve growth in children with $\mathrm{GH}$ deficiency. zinc does not have an effect on growth unless a deficiency is present. In the other studies, some improvement was seen in the indices of zinc status indicating a mild zinc deficiency 
may have been present. Solomons est al. (1976) also concluded that zinc deficiency was not a contributory factor in all cases of short stature. However, five patients with Crohn's disease who experienced growth arrest had some evidence of zinc deficiency. The authors concluded that a normal pattern of growth is consistent with normal zinc nutrition but that a plateau in growth is observed when zinc deficiency is present.

Erom these results, it can be hypothesized that zinc deficiency adversely affects GH levels or synthesis leading to decreased levels of circulating IGF-I. If so, GH treatment would be expected to alleviate the effects of zinc deficiency on growth. Prasad et al. (1969) investigated the effect of bovine $\mathrm{GH}$ (bGH) treatment in zinc deficient rats and of $z$ inc in hypophysectomized rats. For the first part of the study, rats were given a $z$ inc deficient diet for three weeks and then continued on the zinc deficient diet or given supplemental zinc for two weeks. One half of each group received bGH. The control groups were rats given the supplemented diet with or without growth hormone. In the second part, hypophysectomized rats were treated for two weeks as in part one. Dietary $\mathrm{z}$ inc supplementation increased the growth rate of nonhypophysectomized zinc deficient rats considerably while bGH treatment was without effect in the presence or absence of $z$ inc. The growth rate of the hypophysectomized rats was affected by both zinc and $G H$ and these effects were independent. It was concluded that zinc and $\mathrm{GH}$ regulate growth in rats by indepen- 
dent mechanisms. Oner et al. (1984) also investigated the effect of growth hormone treatment in zinc deficient rats. After three weeks of a zinc deficient diet, rats received supplemental zinc, bGH, or saline. As libitum and pair-fed control groups were also included. The zinc deficiency diminished skeletal growth (as measured by tibial epiphyseal width) and decreased serum somatomedin which treatment with bGH did not improve. Zinc repletion restored somatomedin levels to normal and improved body weight gain and skeletal growth. It was observed that despite similar serum somatomedin levels, the GH-treated $z$ inc deficient rats had smaller tibial epiphyseal widths than pair-fed control rats. The authors concluded that zinc deficiency impairs skeletal growth through decreased somatomedin production as well as decreased action of somatomedin on skeletal growth. Zinc was not acting through GH since GH treatment failed to increase epiphyseal widths in zinc deficient rats.

The study design of both studies had limitations. Prasad et al. (1969) did not use pair-fed control groups in his study and oner et al. (1984) did not have a pair-fed group that received bGH. The lack of response may be partially explained by protein energy malnutrition with the rats being unable to respond by increasing growth. The rats were on the zinc deficient diets for five and six weeks respectively with a concomitant decrease in food intake. Swenerton and Hurley (1968) reported that 98 of male rats died after three weeks on 
a zinc deficient diet if not zinc repleted. Prasad et ale (1969) used a pituitary extract which may have been contaminated with other growth factors which could influence growth. Oner et al. (1984) gave the GH for three weeks. Antibody formation occurs when rats are given hGH for two weeks or longer. Neither study specifically measured IGF-I. oner et al. (1984) measured somatomedin activity while Prasad et al. (1969) did not do any somatomedin measurements. 


\section{BTATEMENT OF PORPOSE}

It has been shown that dietary $z$ inc deficiency leads to retarded linear growth in the rat. One mechanism for this impaired growth may be a reduction in circulating growth hormone which, in turn, reduces insulin-like growth factor I (IGF-I). Circulating IGF-I is believed to be a mediator of some of the effects of $\mathrm{GH}$ on linear growth. Previous studies used a bovine $\mathrm{GH}$ preparation to study the effect of $\mathrm{GH}$ treatment on growth in zinc deficiency. Considering the species differences in $\mathrm{GH}$, the suitability of $\mathrm{bGH}$ for the rat may be questionable. Human $\mathrm{GH}$ is effective in the rat and can be used for 14 days before the production of antibodies by the animal. Based on the evidence, it was hypothesized that hGH treatment would increase circulating IGF-I and alleviate the effects of $z$ inc deficiency on growth in rats.

Specific objectives in the experiment were:

(1) to determine the effect of dietary zinc deficiency on nutritional status by measuring:

(a) liver zinc, copper, and iron concentrations

(b) tibial zinc and copper concentrations

(c) plasma zinc concentration

(d) plasma alkaline phosphatase activity, a zincdependent metalloenzyme, as a functional test of zinc deficiency:

(2) to determine the effect of dietary zinc deficiency on 
growth by measuring:

(a) body weight

(b) tail length, a measure of skeletal growth in the rat

(c) tibial epiphyseal cartilage width, a measure of longitudinal growth;

(3) to determine the effect of dietary zinc deficiency on plasma IGF-I levels;

(4) to deternine the effect of $\mathrm{hGH}$ treatment on nutritional status, growth, and plasma IGF-I by comparing parameters between GH-treated and untreated animals. 
CRAPTER II. MATERIAIB NID METHOD8

\section{EXPERIMEATAL DEBIGA}

The experiment was carried out as a completely randomized block design with a $2 \times 3$ factorial combination. The experimental design consisted of three dietary groups: a zincdeficient (ZD) group fed a diet containing < $1.5 \mathrm{ppm} z$ inc ad libitum; a control (C) group fed a diet containing 85 ppm zinc ad libitum; and a pair-fed (PF) group fed the $85 \mathrm{ppm}$ diet to the level of intake of the ZD group. The PF group was included to control for the effects of decreased food intake accompanying zinc deficiency. After 7 days, one-half of each dietary group began to receive hGH dissolved in saline or the saline alone (sham-treated). The experimental design and sample sizes within each block is shown in Figure 2.1 .

heE-treated

\begin{tabular}{|c|c|}
\hline 12 & 12 \\
\hline 12 & 12 \\
\hline 12 & 11 \\
\hline
\end{tabular}

Figure 2.1 Experimental Design 


\section{EXPERIMEITAL PROTOCOT}

All animals were acclimatized for four days on rat chow. After the acclimatization period, the rats were weighed and randomized by weight into the $2 D, C$, or PF dietary groups. The ZD and $C$ groups immediately began their respective diets. The PF rats began their diets one day later since they were fed the $85 \mathrm{ppm}$ diet in the amount that their ZD counterparts consumed the previous day. The first day of the experimental diets is Day 1 of the study.

The food intake of each rat was recorded daily. On Day 1 and every 3 days thereafter, body weight and tail length was measured. Tail length was measured in millimeters from the anus to the tip of the tail. The final measurements were taken 1 day prior to the end of the feeding trial.

Growth hermone treatment began on Day 8. All animals were killed on Day 18 after an overnight fast. Blood was collected by cardiac puncture for determination of plasma zinc, alkaline phosphatase, hGH, and IGF-I. one tibia was removed for measurement of epiphyseal cartilage width. The other tibia and the liver were removed for trace element analysis.

\section{EXPERIKENTAL TECHNIQUEB}

\section{ANIMAL CARE}

Male weanling rats ( 3 weeks old) of the Sprague-Dawley strain were obtained from Charles River Inc. (St. Constance, $P Q)$. The rats were housed individually in stainless steel 
cages with stainless steel grids on the bottom that prevented coprophagy. The room temperature was maintained at $22-25^{\circ} \mathrm{C}$ and lighting was provided automatically for a period of 12 hours daily from 0800 to $2000 \mathrm{~h}$. Control and 2D rats were allowed ad libitum access, and the PF group restricted access, to a pelleted semi-purified diet. Food was placed on the floor of each cage. It was weighed before being placed in the cages. Leftover food and spillage was weighed the next day to determine daily food intake. Deionized distilled water was available ad libitum from plastic water bottles. Single-use plastic gloves were used when handling experimental materials and animals.

\section{HUWAN GROWTH HORYONE (hGH) TREATMENT}

The hGH, an extract from human pituitaries, was obtained from Sigma Chemical Company (St. Louis, MO). The potency was 4 I.U. per mg. For the injections, the hGH was dissolved in saline and administered using a 1 cc Tuberculin syringe fitted with a $26 \frac{1}{2}$ gauge needle (Becton Dickinson, Fisher Scientific, Montreal, PQ). It was administered between 0900 and $1100 \mathrm{~h}$ every day for 10 days beginning on Day 8. All hGH was used within 24 hours after being dissolved in saline since no preservatives were added. The dose was $20 \mu \mathrm{g}$ per $100 \mathrm{~g}$ body weight. Individual dosages for each rat were calculated every 3 days based on changes in body weight. Three injections sites were used: the right hindflank, the left hindflank, and the back of the neck. The sites were rotated daily to prevent 
bruising or other adverse reactions in one area. The injection sites were examined daily. The sham-treated rats were treated in the same manner as the hGH-treated rats.

\section{DIETS}

Experimental diets were purchased from ICN Biomedicals Canada, Ltd. (Mississauga, ON). The composition of the diets is shown in Tables $2.1-2.4$. The $z$ inc content of both diets was determined by flame atomic absorption spectrophotometry after wet digestion in a nitric:perchloric acid mixture. The method is described in Appendix 1. The zinc deficient diet contained $<1.5 \mathrm{ppm}$ of $z$ inc and the control contained $85 \mathrm{ppm}$ of zinc. They were semi-purified, biotin-fortified, egg white diets in a pelleted form. Egg white was used as the protein source since it is a complete protein with the lowest zinc content. The diets were biotin-enriched to control for the avidin, a biotin-chelating agent found in egg white. A pelleted form was chosen for ease of handling and to control spillage. Both diets were stored in plastic bags in sealed buckets and kept in refrigerated storage.

\section{TI8BUE COLLECTION}

All rats were killed on Day 18 of the feeding trial in a fasted state. The rats were anaesthetized with carbon cioxide and blood was withdrawn by cardiac puncture. If possible, two withdrawals were made on each animal. One used a vacutainer (Becton Dickinson, Fisher Scientific, Montreal, PQ) Trace Element Tube coated with sodium heparin for the zinc and 
alkaline phosphatase determinations. Trace Element Tubes have a minimal zinc content $(0.20 \mathrm{ppm})$ and are recommended for trace element determinations. For the hGH and IGF-I determinations, a Vacutainer Tube coated with EDTA was used. EDTA is the recommended anti-coagulant for determination of IGF-I. All blood was centrifuged and the plasma transferred to microeppendorf centrifuge tubes. It was stored at $-80^{\circ} \mathrm{C}$ until analyzed. The EDTA plasma was stored in two aliquots. Following cardiac puncture, the neck of each animal was broken to ensure it was dead. The abdomen was opened and the liver removed, weighed, and kept frozen at $-80^{\circ} \mathrm{C}$. The skin and fur was then removed from the hindflanks and legs. The hind part of each animal was removed intact and kept frozen at $-80^{\circ} \mathrm{C}$.

\section{ANALYTICAL TROCEDUREB}

\section{TIBIAL EPIPHYBEAL CARTILAGE WIDTH}

The measurement of the tibial epiphyseal cartilage width was based on the method of Greenspan et al. (1949). One tibia, from either the right or the left leg of each animal, was dissected free of the surrounding tissue and bone. The calcified portion of the tibia was stained with silver nitrate and the width of the cartilage band was measured with a microscope equipped with a micrometer. The procedure is fully described in Appendix 2. 


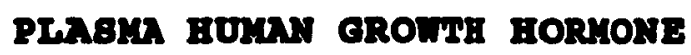

Plasma samples for hGH were thawed and heavily hemolyzed samples were discarded. Plasma hGH was determined with a radioimmunoassay kit manufactured by Diagnostic Products Corporation (Los Angeles, CA). It is a competitive, doubleantibody procedure using ${ }^{125} \mathrm{I}$-labelled hGH. since the kit was intended for human plasma, a tube to account for nonspecific binding by the rat plasma was included.

\section{PLABY IN8ULIN-LIKE GROWH FACTOR I}

Plasma samples for IGF-I were thawed and heavily hemolyzed samples were discarded. The determination of IGF-I was a twostep procedure using a radioimmunoassay kit manufactured by Nichols Institute (San Juan Capistrano, CA). The first step was the extraction of plasma samples and controls to separate binding proteins from the IGF-I. The acid:ethanol extraction procedure included with the kit was modified according. to Takahashi et al. (1990). The modification was recommended since rat plasma contains more IGF binding protein 3 than does human plasma. The extraction procedure is outlined in Appendix 3. The IGF-I in the extracted samples and controls was then determined with a competitive, double-antibody assay using ${ }^{125}$ I-labelled IGF-I.

\section{PLAgMA gINC ND NLXNINE PHOBPHTA8E}

Plasma samples for zinc and alkaline phosphatase were thawed and heavily hemolyzed samples discarded. Plasma zinc concentrations were determined by flame atomic absorption 
spectrophotometry (Perkin-Elmer Model 2380, Perkin-Elmer (Canada) Ltd., Montreal, PQ) after dilution with distilled deionized water. Plasma alkaline phosphatase activity (U/L) was determined by the hydrolysis of p-nitrophenyl phophate (Sigma Chemical Co., st. Louis, MO) and the absorbance of pnitrophenol read at $405 \mathrm{~nm}$.

\section{TIBIA NID LIVER TRACE ELEHENT NARLYBS}

The remaining tibia was dissected free from the surrounding tissue and bone and the fat was extracted with ether (see Appendix 4). The liver and the tibia were placed in acidwashed plastic vials and freeze-dried to a constant weight. They were then sealed until needed. All samples were wet digested using nitric acid according to the method of clegg et al. (1981). Duplicate digestions were done for each liver. zinc, copper, and iron concentrations in the liver and zinc and copper concentrations in the tibia were determined using flame atomic absorption spectrophotometry (Perkin Elmer Model 3100, Perkin-Elmer (Canada) Ltd., Montreal, $P Q$ ). The full procedure for the trace element analysis is outlined in Appendix 5.

\section{TATI8TICAL ANALY8EB}

The experimental design was a 2 by 3 factorial, arranged in a completely randomized design with 12 non-real replicates. A two-way analysis of variance was done using the general linear models (GLM) procedure of the SAS systems (SAS 
Institute Inc., 1985), according to steel and Torrie (1980). Means of variables were separated by Fisher's protected least significant difference (ISD). The level of significance was set at $p \leq 0.05$. The command statements are summarized in Appendix 6. ZINC represents the 3 dietary groups and GHORM represents the 2 hGH treatments. 
Table 2.1 2ine Deficient Diet $(<1.5 \mathrm{ppa} \mathrm{zn})^{1}$ Ingredients $\mathrm{g} / \mathrm{kg}$

Egg White 180

Corn oil 100

Corn Starch 443

Sucrose 200

Alphacel Hydrolyzed 30

Choline Bitartrate 2

Biotin 0.02

AIN-76 Mineral Mixture ${ }^{2} \quad 35$

AIN-76 Vitamin Mixture ${ }^{3} \quad 10$

${ }^{1}$ ICN Biomedicals Canada, Mississauga, ON.

2 Composition of AIN-76 Mineral Mix without zinc is presented in Table 2.4 .

${ }^{3}$ Composition of AIN-76 Vitamin Mix is presented in Table 2.3. 


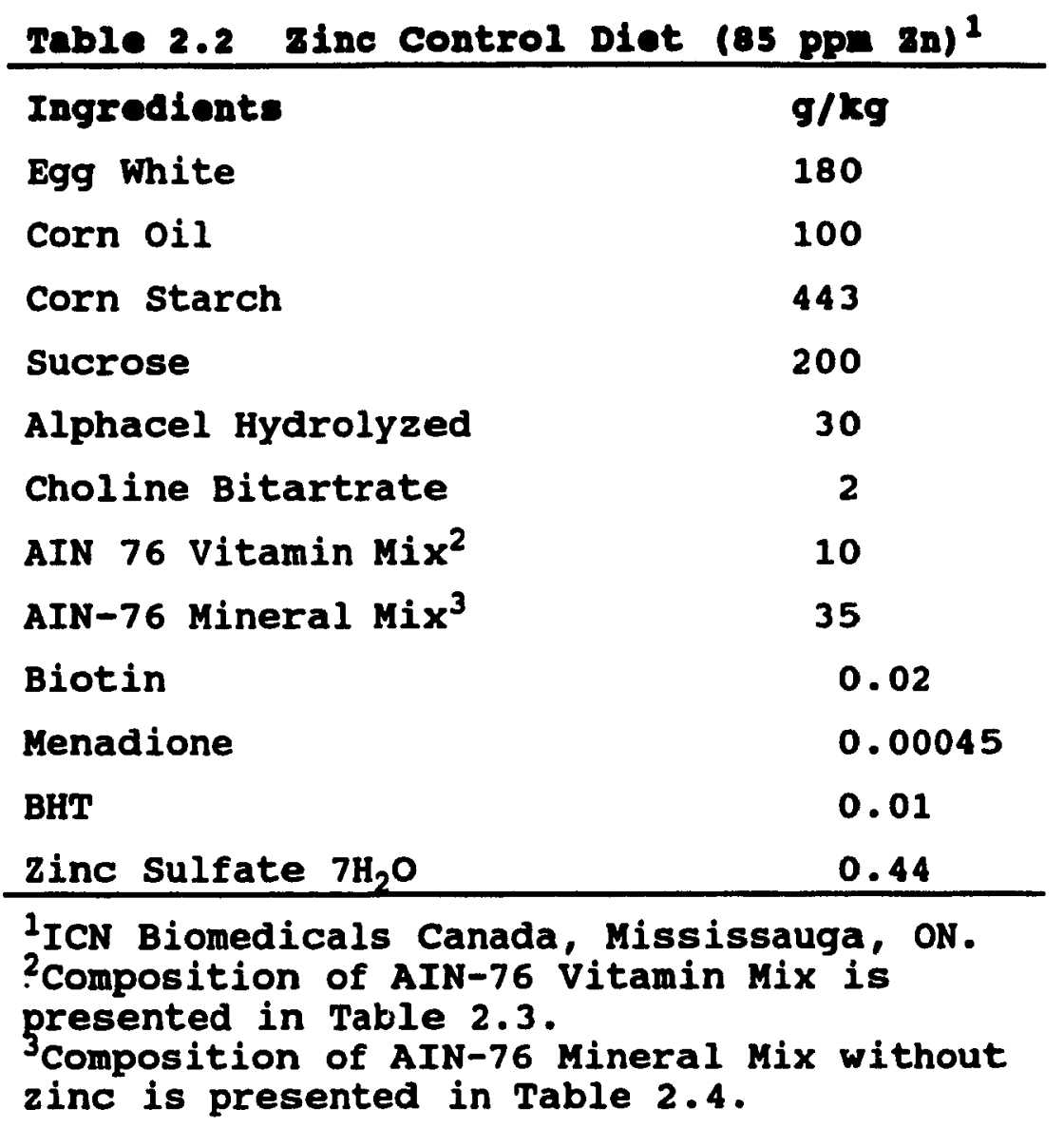


Table 2.3 AIM-76 vitanin Mixture

Ingredient

$\mathrm{g} / \mathrm{kg}$

Thiamin Hydrochloride

0.6

Riboflavin

0.6

Pyridoxine Hydrochloride

0.7

Nicotinic Acid

3

D-Calcium Pantothenate

1.6

Folic Acid

0.2

D-Biotin

0.02

Cyanocobalamin (Vit B-12)

0.001

Retinyl Palmitate (Vit A) $(250,000 \mathrm{IU} / \mathrm{g})$

1.6

DL-alpha-Tocopherol Acetate $(250 \mathrm{IU} / \mathrm{g})$

20

Cholecalciferol (Vit $\left.D_{3}\right)(400,000 \mathrm{IU} / \mathrm{g})$

0.25

Menaquinone (Vit $K$ )

0.005

Sucrose, finely powdered

972.9

${ }^{1}$ ICN Biomedicals Canada, Mississauga, ON. 


\begin{tabular}{lc} 
Table 2.4 MIN-76 Mineral Mixture without $81 \mathrm{~g}^{1}$ \\
\hline Ingredient & $\mathrm{g} / \mathrm{kg}$ \\
Calcium Phosphate Dibasic & 500 \\
Sodium Chloride & 74 \\
Potassium Citrate Monohydrate & 220 \\
Potassium Sulfate & 52 \\
Magnesium Oxide & 24 \\
Manganous Carbonate (43-48\% Mn) & 3.5 \\
Ferric Citrate & 6 \\
Cupric Carbonate (53-558) & 0.30 \\
Potassium Iodate & 0.01 \\
Sodium Selenite & 0.01 \\
Chromium Potassium Sulfate & 0.55 \\
\hline
\end{tabular}

${ }^{1}$ ICN Biomedicals Canada, Mississauga, ON. 
CINPTER III. REBULTB

\section{FOOD IMTAKE NND GROWLH PARAMETERS}

cumulative food intake and growth parameters were analyzed and the data presented in Table 3.1. Growth parameters included body weight gain, change in tail length, liver wet weight, dry, fat-free tibia weight, and tibial epiphyseal cartilage width. Figures $3.1-3.4$ illustrate patterns of food intake, weight gain, and tail length changes. Appendix 7 contains a summary of the analysis of variance for each dependent variable.

FOOD IRMXRE

There was no effect of hGH treatment $(p>0.05)$ on food intake while the effect for zinc in the diet was highly significant ( $p=0.0001 ;$ Table 3.1; Figure 3.1). The three dietary groups were pooled across hormone treatments .and compared. There was no difference in food intake between the zinc deficient (2D) and pair fed (PF) animals; however, food intake for the control (C) group was approximately twice that of both the ZD and PF groups. When compared on a daily basis, this difference in food intake became apparent on Day 4 and continued for the remainder of the feeding trial (Figure $3 . \dot{2}$ ). Except for a slight difference on Day 1 (11.6 g vs $12.7 \mathrm{~g})$, there were no significant differences in food intake on a daily basis between the PF and ZD animals. 


\section{BODY NEICHY GAIX}

The effect of zinc in the diet on body weight gain was significant ( $p=0.0001$; Table 3.1$)$ while no effect ( $p>0.05)$ was attributed to hGH treatment. When the dietary groups were pooled across hGH treatments, the $C$ animals gained more weight $(p<0.05)$ compared to the $\mathrm{ZD}$ and $\mathrm{PF}$ animals. There was no difference between the ZD and PF groups in body weight gain. By Day 4 of the feeding trial, weight gain for the ZD and PF animals began to plateau while the $C$ animals continued to gain substantial weight (Figure 3.3). Initial body weight for the PF group was higher $(p<0.05)$ on Day 1 because these animals began the experimental diet one day later than the ZD and C groups. As a result, body weight throughout the experimental period was approximately 7 grams higher in the PF group compared to the ZD group.

\section{TAII LENGTH}

Human GH treatment had no effect $(p>0.05)$ on tail length growth while zinc content of the diet was significant $(p=0.0001 ;$ Table 3.1). After being pooled across hormone treatments and compared, changes in tail lengtr, were different among all three dietary groups $(p<0.05)$. The largest gain in tail length occurred in the $C$ group and the smallest in the $2 D$ group. The change in the PF group was intermediate. By Day 10, differences in tail length among the three groups were apparent $(p<0.05)$ and continued for the remainder of the feeding trial (Figure 3.4). Initial tail lengths were not 
different.

IIVAR NID TIBIA WEIGIT

Neither liver weight nor tibia weight showed an effect for hGH treatment $(p>0.05)$. The effect of zinc was significant for the weight of both the liver and the tibia ( $p=0.0001$; Table 3.1). When pooled across hGH treatments, liver and tibia weights were different among all three dietary groups $(p<0.05)$. The $c$ group had larger livers and tibiae compared to either the 2D or PF groups. Liver and tibia weights in the PF group were greater than those in the ZD group.

\section{TIBIAL EPIPHYBEA CNRIIIAE NIDTH}

For the tibial epiphyseal cartilage width, a significant interaction occurred between the $z$ inc and hGH $(p=0.0331$; Table 3.1); therefore, the main effects of $z$ inc and hGH could not be considered and the data could not be pooled. Each mean was compared to all other means and the least significant difference calculated $(p<0.05)$. Significant differences occurred between pairs of means when different dietary groups were compared. The means of the ZD groups were significantly different from both PF groups and both $\mathrm{C}$ groups. The means of the PF groups were significantly different from both $C$ groups. No significant difference was found between hGH treated and sham animals within the same dietary treatment. The $c$ groups had larger epiphyseal cartilage widths compared to either the ZD and PF groups while the ZD groups had larger epiphyseal widths than the PF groups. The ZD group receiving hGH had a 
larger epiphyseal cartilage width compared to its respective sham. For the PF and $C$ groups, however, the hGH treated animals had smaller epiphyseal widths compared to the shams.

\section{PLABMA VALUES}

All blood measurements were performed on the rat plasma and included zinc, insulin-like growth factor I (IGF-I), alkaline phosphatase, and human growth hormone. Table 3.2 summarizes the data.

\section{PLABKa zINC}

There was an effect of zinc in the diet $(p=0.0001 ;$ Table 3.2) and of hGH treatment ( $p<0.05 ;$ Table 3.2$)$ on plasma $z$ inc concentrations. When pooled across dietary groups, rats that received hGH had higher concentrations of plasma $z$ inc compared to the sham animals $(p<0.05)$. Plasma zinc also differed among the three dietary groups $(p<0.05)$. The $C$ animals had higher plasma zinc concentrations than either the 2D or PF animals while plasma zinc in the PF group was almost twice that in the ZD group.

\section{PLABYA ALTaIINE PHOBphatage}

Plasma alkaline phosphatase was affected by the zinc level in the diet $(p=0.0001$; Table 3.2$)$ but not by hGH treatment $(p<0.05)$. When dietary groups were pooled, alkaline phosphatase values were different among the three dietary groups $(p<0.05)$. The PF group had higher alkaline phosphatase activity when compared to the $C$ and $2 D$ animals. It was also 
higher in the $C$ animals compared to the $2 D$ animals.

\section{PLABWA IMBULIN-LIKE GROWTH FACTOR I}

There was no effect of hGH treatment $(p>0.05)$ on plasma IGF-I while the effect of zinc in the diet was significant $(p=0.0001$; Table 3.2). When pooled across hormone treatments, the $C$ group had higher plasma IGF-I compared to either the ZD or PF groups $(p<0.05)$. While plasma IGF-I was numerically higher in the PF rats compared to that in the $\mathrm{ZD}$ rats, this difference did not reach statistical significance.

\section{HONAY GROWTH HORYONE}

Human $\mathrm{GH}$ in the rat plasma was not affected by zinc in the diet $(p>0.05)$ but was affected by hGH treatment $(p<0.001$; Table 3.2). When dietary groups were pooled, the rats receiving $h \mathrm{hH}$ had higher $\mathrm{hGH}$ concentrations compared to the sham animals $(p<0.05)$.

\section{TI8BUE MINERAL CONTENT}

The concentration of zinc, copper, and iron was measured in the liver and of $z$ inc and copper in the tibia. The data are summarized in Table 3.3 .

\section{LIVER ZINC}

Liver zinc concentrations were affected by zinc in the diet $(p<0.001$; Table 3.3$)$ but not by hGH treatment $(p>0.05)$. When pooled across $\mathrm{hGH}$ treatment, the $\mathrm{ZD}$ rats had lower liver $\mathrm{zinc}$ compared to either the C or PF animals $(p<0.05)$. There was no difference between liver concentrations in the $C$ and $P F$ 
groups.

\section{IIVER COPPER}

There was an effect of zinc in the diet on liver copper concentrations ( $p=0.0001$; Table 3.3$)$ but no effect attributable to hGH treatment $(p>0.05)$. Liver copper was higher in the PF group compared to either the $C$ or ZD groups (p<0.05). Liver copper concentrations were lower in the $C$ group compared to the ZD group but the difference was not significant.

\section{IIVER IRON}

A significant interaction between $\mathrm{zinc}$ and hGH treatment occurred for liver iron concentrations ( $p<0.05$; Table 3.3). Therefore, main effects of zinc and of hGH were ignored and the data was not pooled. When differences between individual means were examined by LSD $(p<0.05)$, differences occurred when the $\mathrm{ZD}$ group not receiving hGH was compared to the other groups. The exception was the comparison with the PF group receiving hGH. The other significant differences occurred between the PF group receiving $\mathrm{hGH}$ and the two $\mathrm{C}$ groups. All other differences were not significant. In general, the C animals had lower liver iron concentrations compared to the ZD and PF groups. Larger differences in the means occurred between the hGH treated and sham animals in the $\mathrm{ZD}$ and $\mathrm{PF}$ groups.

TIBIAI gINC

For tibial zinc concentrations, a significant interaction 
occurred between $z$ inc and hGH treatment ( $p<0.01$; Table 3.3 ). Main effects were not considered and individual means were compared by LSD $(p<0.05)$. All comparisons were significantly different except for the comparisons between hGH treated and sham animals in the $\mathrm{ZD}$ and PF groups. Tibial zinc tended to be numerically higher in the $c$ groups, intermediate in the PF groups, and lower in the ZD groups.

TIBIAL COPPER

There was a significant interaction between hGH treatment and zinc in the diet for tibial copper concentrations $(p<0.05$; Table 3.3). Main effects were ignored and the animals were not pooled. Individual means were compared using the LSD $(p<0.05)$ and the $2 D$ group receiving $h G H$ was found to be significantly different from all other groups. Mean tibial copper was highest in thi.s group. The $2 D$ and $C$ groups not receiving hGH were also significantly different. There were also significant differences between the PF group not receiving hGH and the $\mathrm{C}$ groups. Tibial copper concentrations tended to be lower in the $c$ groups than in either the $\mathrm{ZD}$ or PF groups. 
Table 3.1 The effect of sinc and hat on food lntake and gronth purnoteren 1,2

Dinterey aroun

her: ret.

gnonetaint

contres

endreend

Cunulative Food Intake $(g)^{3}$

\begin{tabular}{|c|c|c|c|c|c|c|}
\hline $\begin{array}{l}\text { hot } \\
\text { shen }\end{array}$ & $\begin{array}{l}(12) \\
(12)\end{array}$ & $\begin{array}{l}131 \cdot 4 \pm 2.4 \\
131 \cdot 2 \pm 2.3\end{array}$ & $\begin{array}{l}(12) \\
(12)\end{array}$ & $\begin{array}{l}268.5 \pm 5.9 \\
264.0 \pm 7.1\end{array}$ & $\begin{array}{l}(12) \\
(11)\end{array}$ & $\begin{array}{l}131.9 \pm 2.1 \\
128.8 \pm 1.8\end{array}$ \\
\hline $\mathbf{a}$ & $(24)$ & $131.2 \pm 1.6^{a}$ & $(24)$ & $266.2 \pm 4.5^{b}$ & (23) & $130.4 \pm 1.4^{\mathrm{a}}$ \\
\hline & \multicolumn{3}{|c|}{ Cumulativo } & \multicolumn{3}{|c|}{$(g)^{4}$} \\
\hline c) & $\begin{array}{l}(12) \\
(12)\end{array}$ & $\begin{array}{l}25.8 \pm 1.2 \\
22.9 \pm 1.3\end{array}$ & $\begin{array}{l}(12) \\
(12)\end{array}$ & $\begin{array}{l}136.3 \pm 7.2 \\
129.1 \pm 3.8\end{array}$ & $\begin{array}{l}(12) \\
(11)\end{array}$ & $\begin{array}{l}26 \cdot 2 \pm 2 \cdot 3 \\
23 \cdot 2 \pm 2 \cdot 2\end{array}$ \\
\hline & $(24)$ & $24.3 \pm 0.9^{a}$ & $(24)$ & $132.7 \pm 4.1$ & (23) & $24.8 \pm 1.6^{a}$ \\
\hline
\end{tabular}

Liver wet weight $(g)^{5}$

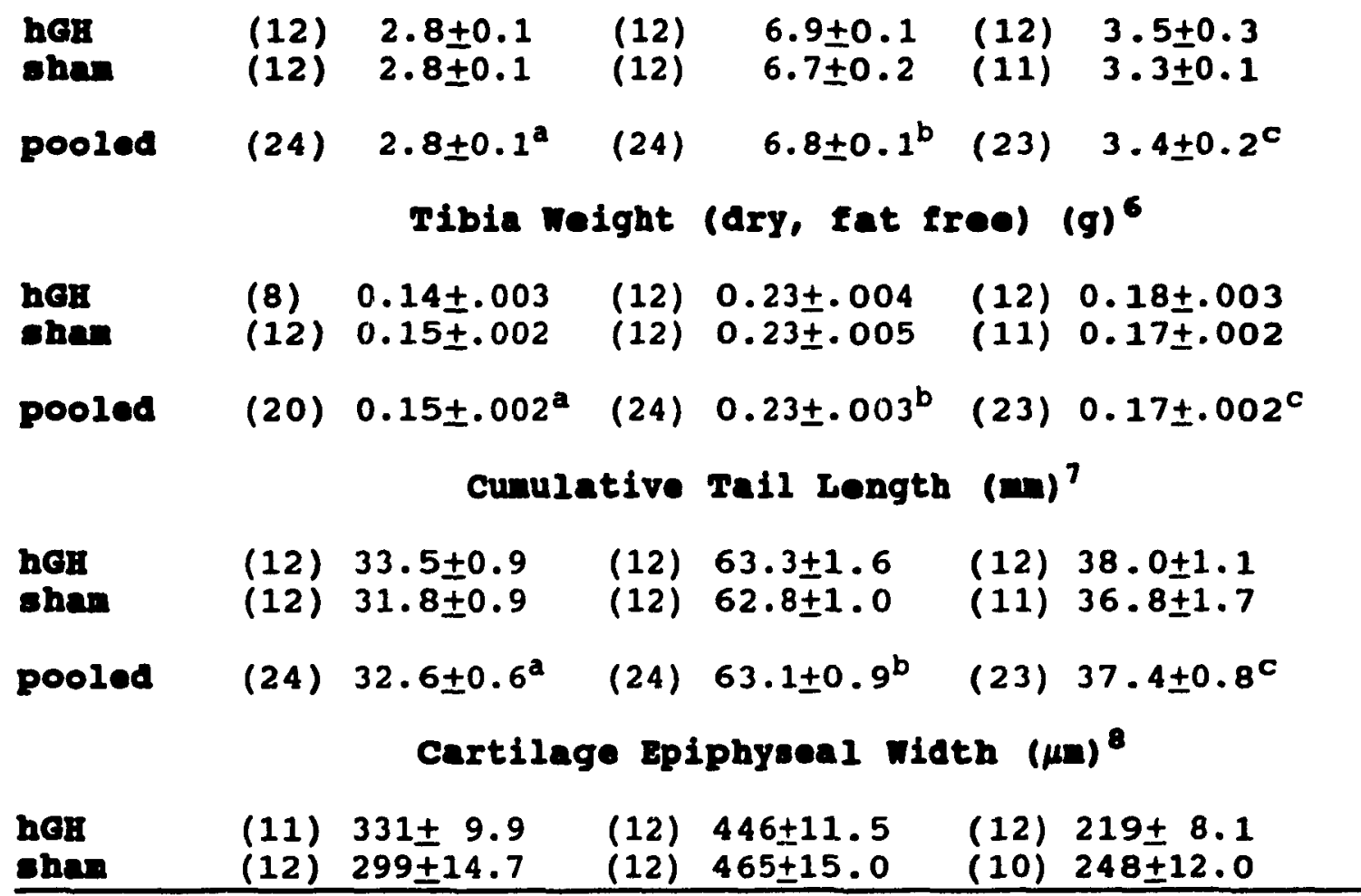

${ }^{1}$ Values are means $\pm S E M$. Numbers in parentheses equals the number of rats.

${ }^{2}$ Means within each parameter having different letter superscripts following the number differ significantly 
$(p<0.05)$ based on the least significant difference.

$3-8$ significance of main effects from analysis of variance (AOV):

3AV: zinc $(p=0.0001)$; hGH (NS); zinc*hGH (NS).

4OV: zinc $(p=0.0001)$; hGH (NS); zinc*hGH (NS).

5AOV: zinc $(p=0.0001)$; hGH (NS); zinc

6AOV: zinc $(p=0.0001)$; hGH (NS); zinc*hGh (NS).

7AOV: zinc $(p=0.0001)$; hGH (NS); zinc*hGH (NS).

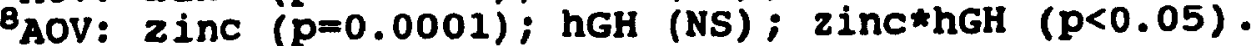


gine $(\mu g / n l)^{4}$

\begin{tabular}{|c|c|c|c|c|c|c|}
\hline $\begin{array}{l}\operatorname{heg}{ }^{a} \\
\text { shamb }\end{array}$ & $\begin{array}{l}(12) \\
(12)\end{array}$ & $\begin{array}{l}0.77 \pm 0.05 \\
0.72 \pm 0.03\end{array}$ & $\begin{array}{l}(11) \\
(12)\end{array}$ & $\begin{array}{l}2.11 \pm 0.13 \\
1.89 \pm 0.08\end{array}$ & $\begin{array}{l}(6) \\
(4)\end{array}$ & $\begin{array}{l}1.59 \pm 0.09 \\
1.28 \pm 0.07\end{array}$ \\
\hline ooled & (24) & $0.75 \pm 0.03^{\mathrm{a}}$ & (23) & $1.99 \pm 0.08^{b}$ & $(10)$ & $1.46 \pm 0.08^{c}$ \\
\hline & \multicolumn{6}{|c|}{ Alkaline Phosphataee $(0 / L)^{5}$} \\
\hline & $\begin{array}{l}(12) \\
(12)\end{array}$ & $\begin{array}{l}66.8 \pm 4.8 \\
75.1 \pm 4.4\end{array}$ & $\begin{array}{l}(11) \\
(12)\end{array}$ & $\begin{array}{l}133.2 \pm 9.1 \\
144.1 \pm 6.3\end{array}$ & $\begin{array}{l}(7) \\
(4)\end{array}$ & $\begin{array}{l}166.8 \pm 15.0 \\
164.4 \pm 13.6\end{array}$ \\
\hline & (24) & $70 \cdot 9 \pm 3 \cdot 3^{a}$ & (23) & $138.9 \pm 5.4^{b}$ & (11) & $164 \cdot 4 \pm 10 \cdot 3^{c}$ \\
\hline & \multicolumn{6}{|c|}{ Insulin-like Growth Factor I (ng/nl) 6} \\
\hline & $\begin{array}{l}(12) \\
(12)\end{array}$ & $\begin{array}{l}141 \pm 8 \\
159 \pm 11\end{array}$ & $\begin{array}{l}(12) \\
(12)\end{array}$ & $\begin{array}{l}764 \pm 54 \\
744 \pm 78\end{array}$ & $\begin{array}{l}(9) \\
(10)\end{array}$ & $\begin{array}{l}200 \pm 23 \\
244 \pm 19\end{array}$ \\
\hline $\mathbf{d}$ & (24) & $150 \pm 7^{a}$ & (24) & $754 \pm 47^{b}$ & (19) & $223 \pm 15^{a}$ \\
\hline \multicolumn{7}{|c|}{ Eunan Growth Hormone $(\mathrm{ng} / \mathrm{nl})^{7}$} \\
\hline & $\begin{array}{l}(7) \\
(8)\end{array}$ & $\begin{array}{l}1.9 \pm 0.5 \\
1.0 \pm 0.0\end{array}$ & $\begin{array}{l}(7) \\
(8)\end{array}$ & $\begin{array}{l}3.9 \pm 1.0 \\
1.0 \pm 0.1\end{array}$ & $\begin{array}{l}(7) \\
(5)\end{array}$ & $\begin{array}{l}2.3 \pm 0.5 \\
1.1 \pm 0.1\end{array}$ \\
\hline
\end{tabular}

${ }^{1}$ Values are means $\pm S E M$. Number in parentheses equals the number of rats.

${ }^{2}$ Means within each parameter having different letter superscripts following the number differ significantly $(p<0.05)$ based on the least significant difference.

"Different letter superscripts following "hGH" and "sham" indicates that the hGH treated animals, pooled across the three dietary groups, differ significantly $(p<0.05)$ from the sham animals pooled.

${ }^{4-7}$ Significance of main effects from analysis of variance (AOV):

AOV: zinc $(p=0.0001)$; hGH $(P<0.05)$; zinckhGH (NS).

5 AOV: zinc $(p=0.0001)$; hGH (NS); zinc*hGH (NS).

6AOV: zinc $(p=0.0001)$; hGH (NS); zinc ${ }^{\text {h }}$ (NH (NS).

${ }^{7}$ AOV: zinc (NS); hGH $(p<0.001)$; zinckhGH (NS). 
Table 3.3 The effect of sinc and hel on tiseue nineral anntent. 1,2

Diatnry eroup

har ort nnopheiainnt

contrel

petrefend

Livex zinc ( $\mu g / g$ dry weight) $)^{3}$

\begin{tabular}{|c|c|c|c|c|c|c|}
\hline $\begin{array}{l}\text { hot } \\
\text { ohen }\end{array}$ & $\begin{array}{l}(12) \\
(12)\end{array}$ & $\begin{array}{l}99.4 \pm 4.2 \\
98.8 \pm 3.0\end{array}$ & $\begin{array}{l}(12) \\
(12)\end{array}$ & $\begin{array}{l}111.4 \pm 2.5 \\
110.7 \pm 2.7\end{array}$ & $\begin{array}{l}(11) \\
(11)\end{array}$ & $\begin{array}{l}109.6 \pm 2.8 \\
113.0 \pm 5.6\end{array}$ \\
\hline ed & $(24)$ & $98.8 \pm 2.5^{a}$ & $(24)$ & $111.0 \pm 1.8^{b}$ & $(22)$ & $111 \cdot 3 \pm 3.1^{b}$ \\
\hline
\end{tabular}

$\begin{array}{lllllll}\text { hot } & (12) & 19.7 \pm 0.7 & (12) & 18.6 \pm 0.4 & (10) & 23.5 \pm 1.1 \\ \text { shem } & (11) & 20.5 \pm 0.5 & (12) & 18.8 \pm 0.4 & (11) & 21.9 \pm 0.9 \\ \text { pooled } & (23) & 20.1 \pm 0.4^{\mathrm{a}} & (24) & 18.7 \pm 0.3^{\mathrm{a}} & (21) & 22.7 \pm 0.7^{\mathrm{b}}\end{array}$

Liver Iron ( $\mathrm{gg} / \mathrm{g}$ ary weight) $)^{5}$

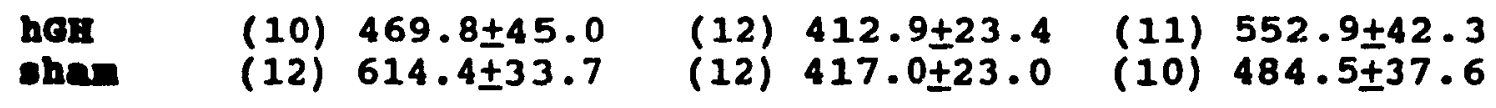

Tibia $\mathrm{zinc}\left(\mu \mathrm{g} / \mathrm{g}\right.$ fat-free, dry weight) ${ }^{6}$

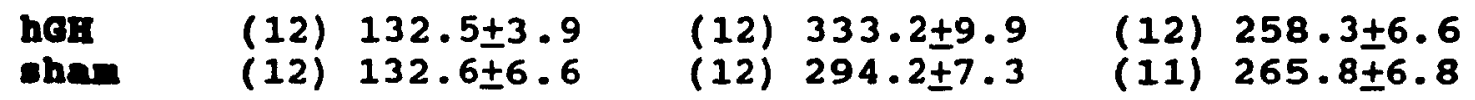

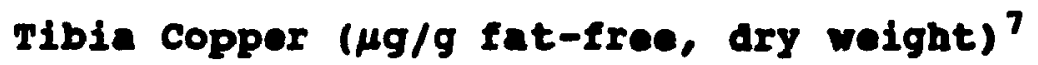

$\begin{array}{llllll}\text { hot } & (12) & 11.5 \pm 0.4 & (12) & 9.6 \pm 0.2 & \text { (12) } 10.0 \pm 0.3 \\ \text { shan } & (11) & 10.4 \pm 0.3 & (12) & 9.5 \pm 0.3 & \text { (11) } 10.5 \pm 0.3\end{array}$

${ }^{1}$ Values are means $\pm S E M$. Number in parentheses equals the number of rats.

Means within each parameter having different letter superscripts following the number differ significantly $\{\underline{p}<0.05)$ based on the least significant difference.

3-7 Significance of main effects from analysis of variance $(A O V)$ :

AOV: 2 inc $(p<0.001)$; hGH (NS); zinckhGH (NS).

AOV: zinc $(p=0.0001)$; hGH (NS); zinc*hGH (NS).

5 AOV: zinc $(p<0.001)$; hGH (NS); zinc*hGH $(p<0.05)$.

6AOV: zinc $(p=0.0001)$; hGH (NS); zinc*hGH $(p<0.01)$.

7AOV: zinc $(p=0.0001)$; hGH (NS); zinc*hGH $(p<0.05)$. 


\section{Figure 3.1 Cumulative Food Intake Effect of Dietary Zinc}

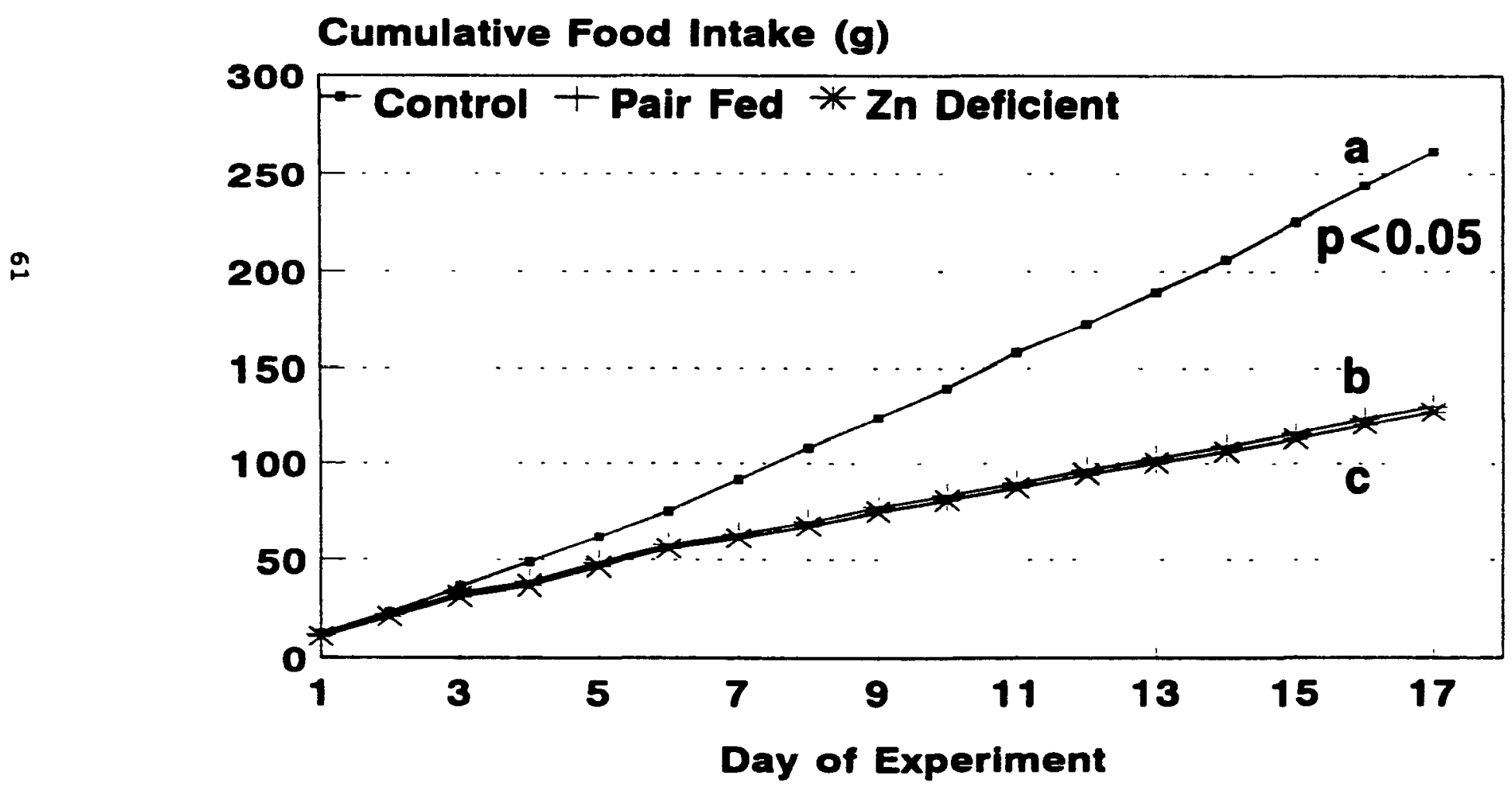




\section{Figure 3.2 Daily Food Intake Effect of Dietary Zinc}

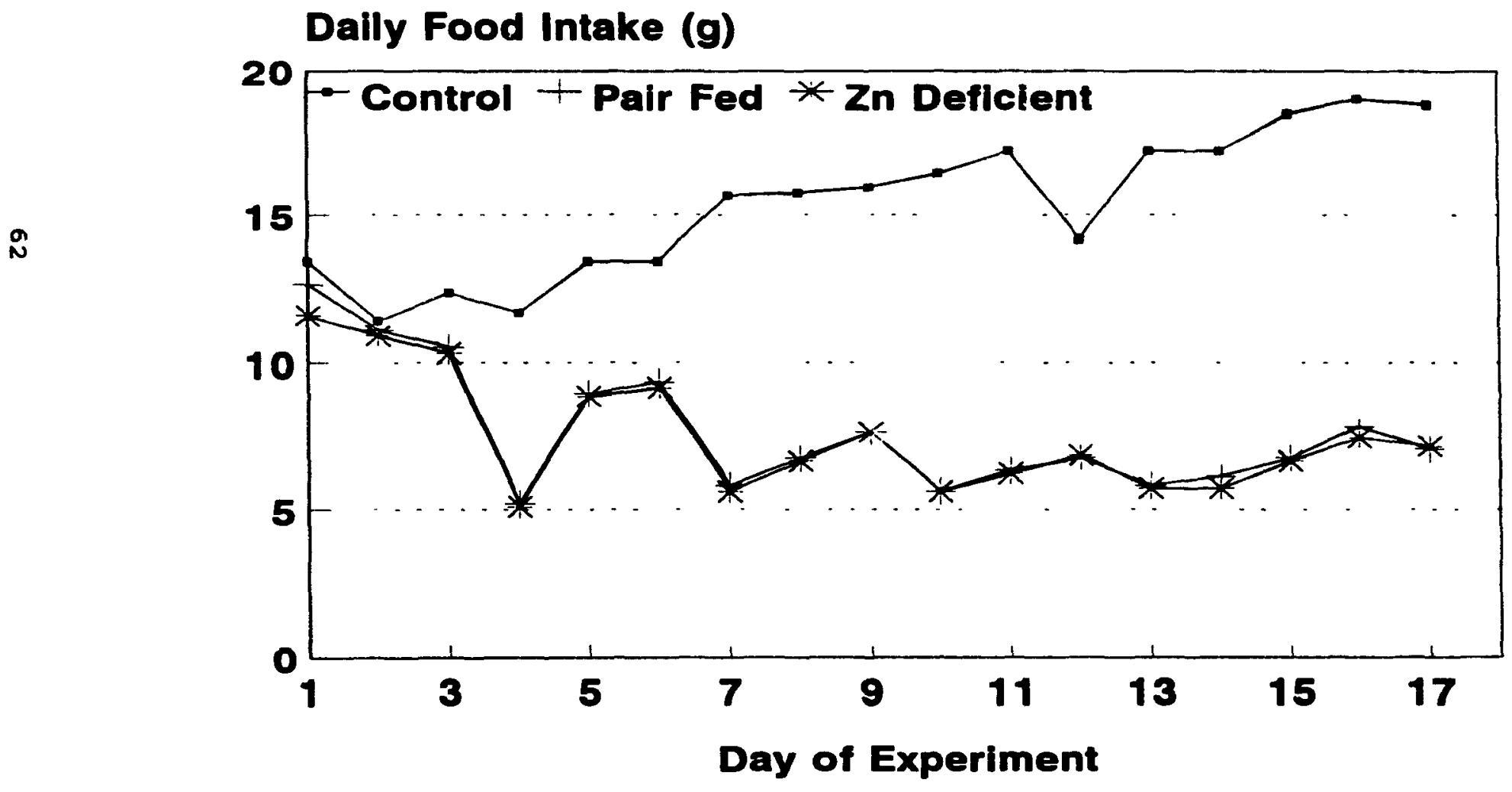


Figure 3.3 Cumulative Weight Gain Effect of Dietary Zinc

ธิ

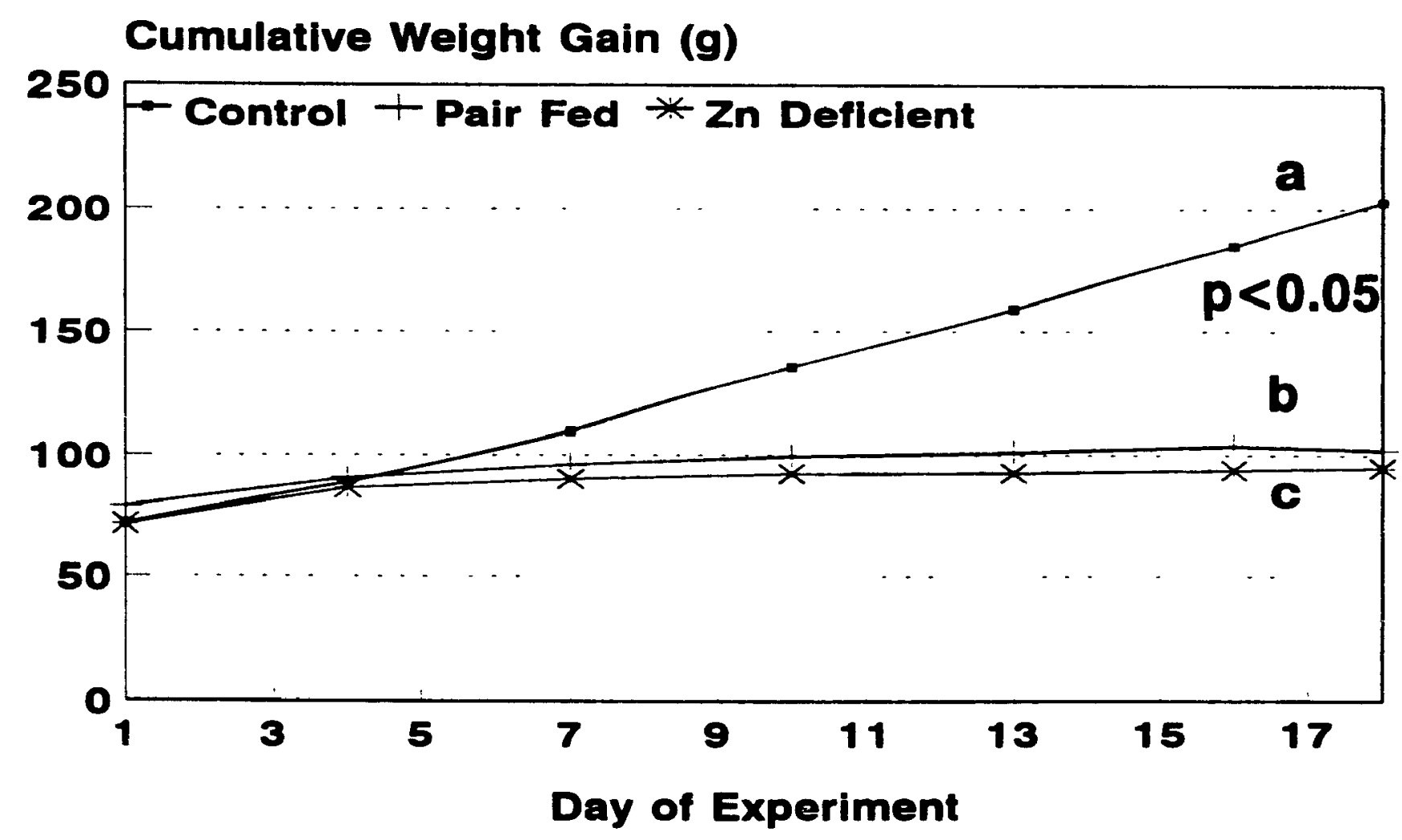




\section{Figure 3.4 Cumulative Tail Length Effect of Dietary Zinc}

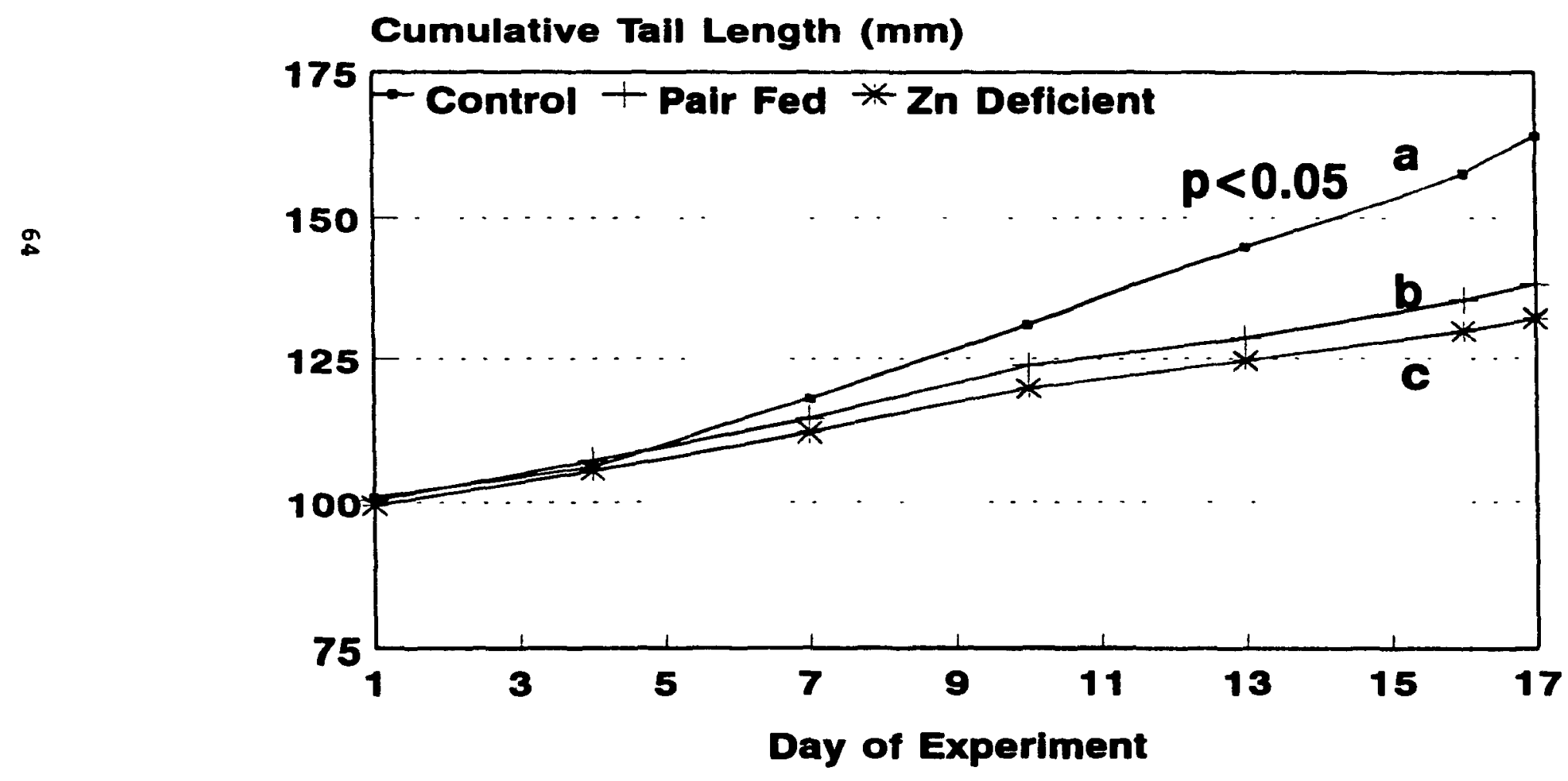




\section{CENPTER IV. DI8C088IOA}

The ability of human growth hormone (hGH) to alleviate the effects of zinc deficiency on growth was investigated. The effects of injecting hGH on growth and nutritional status were compared in three groups of rats: a zinc deficient group (ZD, < 1.5 ppm zinc, ad libitum); a control group (C, 85 ppm zinc, ad libitum); and a pair-fed group (PF, 85 ppm zinc, restricted fed). This was the first study to examine the efficacy of $\mathrm{GH}$ in zinc deficiency using a human GH preparation rather than a bovine GH preparation. It was also the first study to include a pair-fed group to control for the effects of inanition and to investigate the combined effects of hGH and $z$ inc on insulin-like growth factor I (IGF-I) specifically.

\section{NUTRITIONAL BTATU8 OF THE RATB}

The use of $<1.5 \mathrm{ppm} z$ inc in the diet was successful in producing a zinc deficiency in the experimental animals. The ZD groups displayed many of the classical signs of a zinc deficiency, including anorexia, alopecia, poor growth, and tissue zinc depletion.

A decline in food intake occurs rapidly when rats are fed a zinc deficient diet (Swenerton and Hurley, 1968; Williams and Mills, 1970; Cossack, 1984; Hambidge et al., 1986). Within four days of beginning the experimental diet, a significant reduction in food intake occurred among the deficient animals and this decrease in food intake continued 
for the remainder of the study. When the day to day variation in food intake was examined (Figure 3.2), a cyclical pattern was apparent in the intake of the $\mathrm{ZD}$ animals which has been reported to occur with a severe deficiency (Williams and Mills, 1970; Chesters and will, 1973). No such cycling was apparent in the $C$ animals which increased their daily food intake throughout the study except for a slight decrease on Day 12. This increase corresponded to their increasing body weight. The pair-feeding in the PF groups was successfully completed. The daily pattern of food intake was very similar between the $\mathrm{ZD}$ and PF groups and the cumulative food intake was only 1 gram higher in the $\mathrm{ZD}$ group compared to the PF group. This successful pair-feeding can be partly attributed to the use of a pelleted diet which helped to control spillage. As well, the PF rats consumed their feed immediately when it was placed in the cage. There was no opportunity for any wasting of the diet. Human GH did not alter food intake between the $\mathrm{hGH}$ and sham groups.

Upon visual inspection, it was apparent that the ZD rats in the study were beginning to experience mild alopecia, or hair loss, which is a well-recognized feature of $z$ inc deficiency (Swenerton and Hurley, 1968; NRC, 1978). Their hair coats were more sparse and had a greyish tinge compared to that of the $c$ animals. There was very little fur on the abdomen area of the ZD animals. The PF animals showed no sign of hair loss with hair coats identical to those of the $c$ group. The 
deficiency had not progressed to the point of causing dermal lesions in the ZD animals. Figure 4.1 is a photograph of a $C$ rat (bottom, near ruler) and a ZD rat (top) one day prior to sacrifice. Both animals were injected with hGH; however, hGH had no apparent effect on the rats' hair coats. From this photograph, it is possible to distinguish the difference in the hair coats of the two animals.

Growth measurements included cumulative body weight gain, tail length gain, tibial epiphyseal cartilage width, liver weight, and tibial weight. while all measurements were affected by zinc in the diet, only cartilage epiphyseal width showed any effect of hGH injections.

The decrease in cumulative body weight gain, a measure of overall growth, appeared to be entirely the result of the decrease in food intake. While relatively small compared to the effect of lowered food intake, many investigators report an additional effect of zinc deficiency on weight gain. In the present study, the cumulative weight gain of the $c$ group was five times that of the other two groups while the weight gains for the ZD and PF groups were identical indicating a lack of effect for zinc. Cossack (1984) and Bolze et al. (1987) in studies of similar length reported a significant decrease in weight gain per day for ZD rats compared to PF rats. Cossack (1986) also found that zinc depressed weight gain per day when food intake was held constant and the zinc content was varied among experimental groups. In contrast, 
(

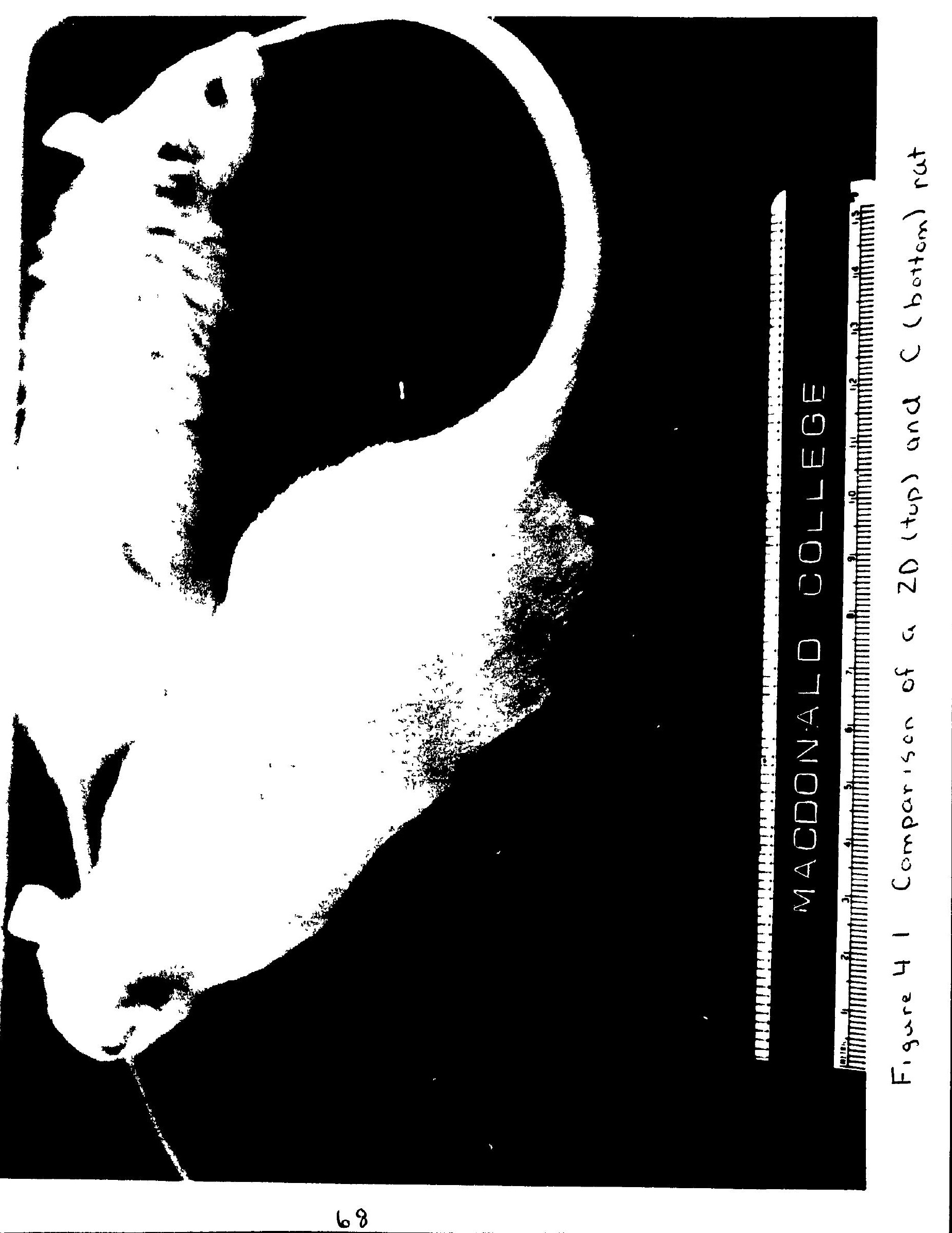


Oner et al. (1984) did not find a significantly greater weight gain in pair-fed rats compared to zinc deficient rats. It is interesting to note that the weight gain in the groups receiving hGH were slightly higher than their respective shams which may reflect the general anabolic nature of growth hormone.

Tail length is considered a measure of longitudinal growth in the rat since the tail contains vertebral bodies. cumulative gain in tail length followed the expected pattern showing a small effect of zinc deficiency in addition to the larger effect of decreased food intake. Tail length was not measured in previous studies where zinc deficiency was induced; therefore, it is difficult to make comparisons. Final tail length in the $C$ group (164 mm) was comparable to that reported in other literature (Prewitt et al., 1982; Fliesen et al., 1989). It can be safely assumed that growth was normal in the $C$ animals and the effects in the $\mathrm{ZD}$ and $\mathrm{PF}$ groups were the expected results of the experimental diets. Decreased linear growth is the usual feature of zinc deficiency. In comparison to body weight, therefore, tail length may be a more sensitive index of growth in relation to zinc deficiency.

The decreased tibial weights and liver weights in the $2 D$ rats compared to the $C$ and $P F$ animals also reflected the general growth retardation accompanying the zinc deficiency in these animals. These results agreed with Swenerton and Hurley 
(1968) who reported lower femur weights and lower liver weights in zinc deficient rats. When comparing the mean tibial and liver weights for the three diet groups (Table 3.1), it is apparent that the lowered food intake had the greater effect on these organ weights. The effect of decreased $z$ inc in the diet, as reflected by the difference between the $\mathrm{ZD}$ and $\mathrm{PF}$ groups, is relatively small although significant.

The final growth parameter was the measurement of the tibial epiphyseal cartilage width. The analysis of variance indicated a significant interaction between hGH and $z$ inc pointing to a possible effect of hGH administration on growth. When the six group means ( 2 hGH treatments by 3 diets) were compared individually, the differences between the hGH treated animals and their respective shams were found not to be significant. The significant differences occurred between the various diet treatments. Human $\mathrm{GH}$ had no effect on epiphyseal cartilage width. These results are in agreement with those of Oner et al. (1984) who administered bovine GH treatment to zinc deficient rats and failed to show any $\mathrm{GH}$ effect on growth, alkaline phosphatase, or tissue zinc. In the present study, for the ZD animals, the epiphyseal width in the hGH group was approximately $32 \mu \mathrm{m}$ larger compared to the shams. The opposite trend was found in the $\mathrm{C}$ and PF groups where the epiphyseal width was smaller in the hGH treated animals. Another unexpected result was the lower mean epiphyseal width 
in the PF groups compared to the $\mathrm{ZD}$ groups. It was expected that the ZD rats would have the smallest epiphyseal widths of the three dietary groups (Oner et al., 1984). This was not the result of tibial weight since the PF group had larger tibia than the $\mathrm{ZD}$ group. Thus, the results in the PF rats are not readily explainable and may be a unique phenomenon in this study.

Plasma alkaline phosphatase, a zinc metalloenzyme used as a functional test of zinc deficiency, devreases in zinc deficiency (Hambidge et al., 1986). As was expected, alkaline phosphatase was decreased in the $\mathrm{ZD}$ animals compared to the $C$ and PF groups; however, the enzyme was unexpectedly higher in the PF animals compared to the $C$ animals. In the only other study similar to the one reported here, oner et al. (1984) found that in the pair-fed rats, alkaline phosphatase was lower than the controls. A partial explanation of the present results may be the small number of samples available for analysis in the PF groups which may have altered the true mean. The variation was larger in the PF and $C$ groups compared to the $2 D$ rats. Overall, the values for alkaline phosphatase were much lower in this study compared to those of oner et al. $(1984)$.

The zinc content of the plasma, liver, and tibia confirmed the development of a zinc deficiency in the ZD animals and corresponded to the results reported in the literature (Swenerton and Hurley, 1968; Cossack, 1984; 1986; Hambidge est 
al., 1986). In the ZD group, the values for these parameters were always lower compared to the C and PF groups. Values for the $C$ and PF rats were similar or lower in the PF group. In comparison to the lowered food intake, the lack of zinc in the diet had the greater effect on decreasing tissue zinc content. Actual values for these parameters are comparable to those of Cossack (1984; 1986) who used similar analytical procedures for $\mathbf{z i n c}$ determinations.

Plasma zinc responds relatively quickly to $z$ inc depletion. Both the decreased zinc intake and food intake influenced plasma zinc values since the PF rats had intermediate values compared to the other animals. Human $G H$ had an apparent effect on plasma zinc which was higher in the animals receiving hGH. Oner et al. (1984) showed no increase in serum zinc when $\mathrm{bGH}$ was given to $\mathrm{ZD}$ rats. Studies in humans also have reported no increase of serum $z$ inc in response to $\mathrm{GH}$ therapy (Cheruvanky et al., 1982; Richards and Marshall, 1983). The increase in plasma zinc levels for the $\mathrm{ZD}$ rats in this study was also much smaller than the increases for the $c$ and PF groups; therefore, the effect may not be as great for the deficient animals.

While liver zinc in the ZD group was decreased, there was no difference between the $C$ and PF animals. Liver zinc levels were affected by the level of zinc in the diet and not by depressed food intake. Cossack (1984; 1986) also reported similar liver zinc values for pair-fed and control animals. 
An interaction between hGH and zinc was observed for the zinc content of the tibia. In the $c$ rats, tibial zinc was significantly higher in the hGH treated animals compared to the shams but this increase did not occur in the PF and $Z D$ groups. Ignoring the interaction, tibial zinc declined in both the $\mathrm{ZD}$ and PF animals with a more substantial decline for the 2D groups. This result would be in agreement with earlier reports of Cossack $(1984 ; 1986)$. Similar results have been shown for the femur as well (Oner et al., 1984; Hambidge et al., 1986; Bolze et al., 1987).

Plasma and bone tend to show a more marked reduction in zinc content in the zinc deficient state compared to the liver (Hambidge et al., 1986; Park et al., 1986). When the values for plasma, lj.ver, and tibial $z$ inc in the $2 D$ groups are comparea, plasma and tibial zinc did show greater decreases in zinc content in response to the lack of dietary $z$ inc compared to the liver. Plasma and tibial zinc would appear to be more sensitive indicators of zinc status for the rat.

Liver iron and copper and tibial copper were analyzed since these minerals interact with zinc. Prasad et al. (1969) found an inverse relationship between $z$ inc supplementation and iron content of liver, bone, and other tissues. Wallwork et al. (1981) did not find a significant effect of dietary zinc on iron and copper in the liver and femur although values for both minerals tended to be lower as dietary $z$ inc increased. In the present study, the lowest mineral values were consistently 
in the $C$ group although not always significant. Results for the PF and ZD groups were variable. Liver copper was highest in the PF animals but tibial copper was highest in the $\mathrm{ZD}$ animals. The interaction between $h \mathrm{hH}$ and $\mathrm{zinc}$ for liver iron was the result of significantly higher iron concentrations in the 2D sham group and in the PF hGH treated group. The interaction for tibial copper occurred because of the high copper content in the $\mathrm{ZD}$ animals who received $\mathrm{hGH}$. While the interactions were significant, there was no consistent effect for hGH treatment on mineral content in these tissues when the means were individually compared. These results support a mineral interaction with high dietary zinc decreasing iron and copper concentrations.

PLABKA INBULIN-LIKE GROWTH FACTOR I

Plasma IGF-I was significantly lower in the PF and $\mathrm{ZD}$ groups compared to the $C$ group. Numerically lower plasma IGFI levels were found in the ZD group compared to the PF group but the difference did not reach statistical significance (LSD $=87.6$ at $p<0.05)$. This would indicate that IGF-I declined because of decreased food intake only with no decline attributable to a lack of $z$ inc in the diet. These results are contradictory to the work of oner et al. (1984) and cossack (1984; 1986; 1988) who all found a small but separate effect of zinc on IGF-I. In a study by Bolze et al. (1987), somatomedin activity in the $2 D$ rats was 75 percent of $P F$ levels but not statistically significant at the end of 
depletion. Somatomedin activity in the PF animals normalized within 48 hours while recovery of somatomedin activity in the 2D rats did not occur until Day 8 which suggested an additional effect of zinc on somatomedin activity. Therefore, this decline in IGF-I may be a biologically important result of the zinc deficiency although it was not statistically significant.

A direct comparison of the values in this study with those of earlier work is difficult. Oner et al. (1984) measured extracted serum IGF-I, Bolze et al. (1987) measured somatomedin activity, and Cossack $(1984 ; 1986 ; 1988)$ measured unextracted IGF-I. The values in all studies were expressed as $U / m l$ in reference to a pool of normal rat serum or plasma designated to contain $1 \mathrm{U} / \mathrm{ml}$. In this study, IGF-I was extracted from its binding proteins using acid:ethanol and was expressed in $\mathrm{ng} / \mathrm{ml}$ in relation to human IGF-I standards. Acid extraction yields results which are two to three times greater than untreated plasma. Therefore, we can only compare the trend in values among the various studies. In this study, IGF-I was highest in the $C$ animals, intermediate in the PF, and lowest in the ZD group. The effect of lowered food intake was much larger than that for the decreased dietary zinc.

Because very few authors expressed IGF-I as $\mathrm{ng} / \mathrm{ml}$, it was difficult to determine whether values obtained in this study were normal for the rat. One study by Thissen et al. (1990) reported serum IGF-I values of $713 \pm 53 \mathrm{ng} / \mathrm{ml}$ for normal 
female rats while another study (Thissen et al., 1991) reported values of $1186 \pm 123 \mathrm{ng} / \mathrm{ml}$. They extracted the binding proteins using a filtration column. In general, IGF-I values tend to exhibit large variations. Acid extraction, which was the method of analysis in this study, may leave residual binding proteins which can interfere with some RIA's (Daughaday and Rotwein, 1989). This is particularly true for rat plasma which has higher insulin-like growth factor binding protein (IGFBP) concentrations. Two human controls with known IGF-I were extracted and assayed along with the rat samples. Results were consistent between assay runs and fell within the specified range of concentrations. However, it is possible that the acid extraction did not remove all IGFBP's in our rat plasma and the values given here are lower than true values. EFPECT OF HUYN GROWTH HORMONE

Treatment with hGH failed to improve indices of growth or alter plasma IGF-I in the zinc deficient rats. One concern is the absorption of the injected hGH. We used a commercial kit designed to assay hGH in human serum or plasma. Any matrix differences between human plasma and rat plasma may have made it difficult to detect the hGH. There was some non-specific binding when rat plasma was incubated alone with the labelled GH. Mean values for the hGH was $1.0 \mathrm{ng} / \mathrm{ml}$ in the sham animals and $2.7 \mathrm{ng} / \mathrm{ml}$ in the $\mathrm{hGH}$ treated animals. Some cross reactivity occurred since the shams, who received no hGH, failed to show a concentration of $0 \mathrm{ng}$ for the assay. It was 
assumed that the injected hGH was absorbed into the rat circulation since only the hGH treated animals had values above $1 \mathrm{ng} / \mathrm{ml}$.

We failed to show a response to hGH not only in the $2 D$ group but also in the $C$ group who should have shown an increase in circulating IGF-I in response to the hGH injection. We chose the dose, $20 \mu g$ per $100 \mathrm{~g}$ body weight, based on the work of Prasad et al. (1969). Thissen et al. (1990) required $400 \mu g$ of recombinant $\mathrm{GH}$ to increase serum IGF-I two-fold in normal protein-deprived rats. Other studies have used equally large doses. It would appear that the lack of response in the present study is the result of the insufficient dose of $\mathbf{G H}$.

Because of lowered food intake, protein energy malnutrition accompanies $z$ inc deficiency in the rat. In humans, as well, zinc deficiency often occurs with protein energy malnutrition (Golden and Golden, 1979). Nutritional variables may be equally as important as $G H$ in regulating IGF-I levels (Furlanetto, 1990). Protein and/or energy restriction has been shown to depress IGF-I levels in rats (Phillips and Young, 1976; Price et al., 1979; Prewitt et al., 1982) and in humans (Isley et al., 1983; Clemmons et al., 1985). In these nutritional insults, the mechanism(s) for the depression of IGF-I have not been a simple decline in circulating GH levels. Fasting appears to decrease GH binding in the liver because of reduced numbers of GH receptors (Maes et al., 1983; 1984a; 
1984b). A post-receptor defect appears to occur with protein deprivation which blunts an animal's response to exogenous $\mathrm{GH}$ (Maes et al., 1988; Maiter et al., 1988). Thissen et al. (1991) also suggested that protein deprivation causes resistance to IGF-I at the organ level and reduces synthesis of IGFBP-3. Normalization of circulating IGF-I failed to promote growth in protein deprived rats. It is increasingly apparent that nutritional sufficiency is essential for IGF-I to promote growth (Thissen et al., 1990). A zinc deficient rat is not in a state of nutritional sufficiency. If these events were occurring in the zinc deficient animal as a result of its lowered food intake, it may also be difficult to detect the animal's response to exogenous $\mathrm{GH}$. Alternatively, the $z$ inc effect on IGF-I may be mediated through one of these other mechanisms.

Buzoraliy

The present study confirmed the reports of previous investigators who showed that IGF-I (or SM-C or somatomedin activity) declines in zinc deficient rats. While IGF-I levels were not significantly different between the $7, D$ and $P F$ animals, a marked decline was apparent in the $\mathrm{ZD}$ groups. Together with earlier work, it is probable that zinc has an effect, separate from decreased food intake, on circulating IGF-I levels.

The hypothesis behind the present study was that zinc deficiency decreased circulating growth hormone which, in 
turn, depressed circulating IGF-I levels with resultant subnormal linear growth. We have neither proved nor disproved this hypothesis since the hGH treatment was inadequate and the lack of effect is due to the low dose of hGH. The dose may be another problem concerning the studies of Prasad et alde (1969) and oner et al. (1984) who used $20 \mu \mathrm{g}$ and $40 \mu \mathrm{g}$ of bGH respectively and failed to show an effect in zinc deficiency. If large doses of GH are needed for a response to occur in the rat, a question arises concerning the biological importance of both the dose and the response. Future research should explore other possible mechanisms.

The original somatomedin hypothesis, which stated that circulating IGF-I influenced growth in an endocrine manner, has been expanded to include autocrine and paracrine IGF-I and activities. It is possible that the decline in circulating IGF-I does not play a significant role in the retarded growth accompanying zinc deficiency. Thus, it is important to determine the relevance of this decline in endocrine IGF-I in zinc deficiency. One method is to treat zinc deficient rats with IGF-I. Larger quantities of IGF-I are becoming available for research purposes because of recombinant technology.

Events that take place at the level of the liver mediate the effects of protein and/or energy malnutrition on IGF-I. Instead of lower levels of $\mathrm{GH}$ in circulation resulting in the decline in circulating IGF-I with zinc deficiency, this decline in IGF-I levels may be mediated through a mechanism at 
the level of the liver. Growth hormone resistance or a decline in $\mathrm{GH}$ receptors may occur which would both decrease IGF-I synthesis. Circulating IGF-I is also dependent upon the availability of IGF binding proteins, especially IGFBP-3. The lack of available zinc may be inhibiting synthesis of the binding proteins. Future research should focus on these possible mechanisms and whether any are influenced by the level of zinc in the diet.

Zinc may also influence IGF-I at the level of the tissue, ie. autocrine or paracrine activities. Schlecter et al. (1986a) developed a method whereby rats are cannulated and substances, such as GH or IGF-I, are infused directly into the limb. A similar procedure could be done in zinc deficient rats and the local effects of $\mathrm{GH}$ and IGF-I studied. This method is useful since the opposite leg of the same animal can act as a control. Alternatively, the development of an in vitro system, such as that of Scheven et al. (1991), would be worthwhile for isolating the specific effects of zinc at the local tissue level.

The applicability of these results to humans is unknown. One concern regarding the extrapolation of results to humans is the severity of the zinc deficiency. Most studies, including the present one, produced a severe deficiency in the animals. Zinc deficiency in humans is usually marginal or mild with a severe one occurring under unusual circumstances. A more appropriate approach would be to induce a mild 
deficiency in the rat and to determine its ef fect on IGF-I. Another problem is the lack of studies in this area. GhavamiMaibodi et al. (1983) found that somatomedin-c increased after oral zinc supplementation in short children but Payne-Robinson et al. (1991) found no significant association of zinc with IGF-I in young malnourished children when they controlled for the malnutrition. No other studies have investigated the effect of $z$ inc on IGF-I in humans; therefore, studies using a human model of zinc deficiency would help to clarify the relationship between zinc and IGF-I.

\section{CONCLUBION}

In the present study, zinc deficiency in the rat reduced food intake with a cyclical pattern of intake developing. Tissue zinc content was significantly reduced and showed a greater effect of dietary $z$ inc compared to the decr'sased food intake. Plasma and tibia zinc showed a greater response to the zinc deficiency compared to liver zinc. Tissue iron and copper showed a competitive interaction with zinc and was lower in the animals receiving the $85 \mathrm{ppm} z$ inc diet. There was no consistent effect of lowered food intake on tissue copper and iron. Zinc deficiency also decreased plasma alkaline phosphatase.

Growth retardation also accompanied the zinc deficiency. Body weight gain was significantly reduced by the lowered food intake but showed no separate effect for dietary zinc. Tail length showed a small but separate effect of the $z$ inc 
deficiency in addition to the larger effect of decreased food intake. Both tibia and liver weight were reduced by the dietary zinc deficiency and the lowered food intake. The effect for $z$ inc was the smaller of the two effects. Tibial epiphyseal cartilage width was greater in the zinc deficient animals compared to the pair fed animals.

The present study also showed a possible effect of zinc on free IGF-I. While not significant, IGF-I was lower in the zinc deficient group compared to the pair fed group. Lowered food intake caused the more substantial decrease in IGF-I.

As demonstrated here, both the lowered zinc intake and the lowered food intake contribute to the effects seen with zinc deficiency; however, the effects are not equally distributed. It is the zinc intake which has the most significant effect on mineral content in the various tissues. Growth parameters, however, show a greater effect for the lowered food intake with a relatively small effect attributable to zinc. Plasma IGF-I also shows a greater response to the lowered food intake compared to the lack of zinc. 


\section{APPENDIX 1. DEPERMINATION OF 8 INC IN TRE DIET}

1. Dry the sample in a drying oven at $56^{\circ} \mathrm{C}$ overnight.

2. Grind the sample to a fine powder.

3. Weigh $0.5 \mathrm{~g}$ of sample and place in a digestion tube.

4. Add concentrated nitric and perchloric acids in a ratio of $5: 1$ (approximately $10 \mathrm{ml}$ ).

5. Place the tube in the digestion unit and digest the sample at $180-200^{\circ} \mathrm{C}$ until the brown fume disappears.

6. Transfer the remaining solution to a $50 \mathrm{ml}$ volumetric flask and bring to volume with distilled deionized water.

7. Analyze the zinc content with flame atomic absorption spectrophotometry using a Perkin-Elmer spectrophotometer (Model 3100, Perkin-Elmer (Canada) Ltd., Montreal, PQ). 


\section{APPEIDIX 2. TIBIAI CARTILIGE BPIPAY8TN VIDTH}

1. Dissect the tibia free from the surrounding soft tissue and bone. Care must be taken to keep the epiphysis intact.

2. Split the tibia with a sharp razor in the mid-sagittal plane.

3. Soak the tibial halves in water for one-half hour.

4. Immerse the the tibial halves in acetone for une hour.

5. Soak the tibial halves again in water for one-half hour.

6. While the tibial halves are soaking, prepare the $28(\mathrm{w} / \mathrm{v})$ silver nitrate solution and the $108(w / v)$ sodium thiosulfate solution.

7. Soak the tibial halves in the $2 \%$ silver nitrate solution for $1-2 \frac{1}{2} \mathrm{~min}$. Immediately rinse with water.

8. Place the tibial halves in water and expose them to a strong light source until the calcified portions appear dark brown. The cartilage section should remain clear and gelatinous in appearance.

9. Immerse the tibial halves in the $10 \%$ sodium thiosulfate solution for $25-30 \mathrm{sec}$.

10. Wash the tibial halves several times with water and then soak them in water for one-half hour.

11. Measure the width of the cartilage under the high power of a microscope fitted with a micrometer. Make 8-10 readings across the cartilage section and average the readings to give the width of cartilage band. 


\section{APPHDIX 3. ACID EXYRACTION OF IGF-I BINDINC PROTEIUB}

1. EDTA plasma samples are thawed at room temperature.

2. Pipet $10 \mu 1$ of sample or control into a $1.5 \mathrm{ml}$ microeppendorf centrifuge tube. Add $40 \mu l$ of a hydrochloric acid:ethanol mixture ${ }^{1}$ and thoroughly mix with a votex.

3. Incubate at room temperature for $30 \mathrm{~min}$.

4. Centrifuge at $3500 \mathrm{rpm}$ for $30 \mathrm{~min}$ in a refrigerated centrifuge. A white precipitate will form.

5. Pipet $10 \mu l$ of the supernatant (containing the free IGF-I) into a $10 \times 75 \mathrm{~mm}$ disposable plastic (polystyrene or polypropylene) culture tube. Add $1.4 \mathrm{ml}$ of phosphate buffer containing $300 \mathrm{mg} \operatorname{Tr}$ is base $/ \mathrm{l}^{2}$ and thoroughly mix with a vortex. At this point, the samples can be stored at $4^{\circ} \mathrm{C}$ for one week. The supernatant fraction (100 $\left.\mu l\right)$ contains 1 Hl sevenfold diluted plasma.

6. For the radioimmunoassay, pipet $100 \mu \mathrm{l}$ of the supernatant fraction into another $10 \times 75$ disposable plastic culture tube. Follow the procedures as outlined in the RIA.

1 For the hydrochloric acid:ethanol mixture $(1: 7, v / v)$, combine: $21.6 \mathrm{ml}$ concentrated hydrochloric acid $103.4 \mathrm{ml}$ distilled deionized water $875 \mathrm{ml}$ absolute ethanol.

2 For the phosphate buffer, add $300 \mathrm{mg}$ of Trizma base (Sigma, St. Louis, MO) to 1 L of phophate buffered saline (pH 7.6) (Sigma, st. Louis, MO). 


\section{APPEADIE 4. FAT EETRACTIOI OF TYR TIBIA}

1. Dissect the tibia free of the surrounding tissue and bone.

2. With a fine-pointed needle, make a hole in both ends of the bone to facilitate extraction. Care must be taken to prevent the bone from splitting.

3. Soak the bone overnight in methanol.

4. Using the Soxelet System for fat extraction, place several bones in each column of the system. Label the bones by tying different colored thread around the bone. If available, india ink with a fine tip pen can also be used.

5. Extract the fat with petroleum ether for approximately 6 hours.

6. Remove the bones from the extraction apparatus and air dry in the fume hood overnight.

\section{APPESDIX 5. DETERYINATION OF TRACE ELEYENTS}

1. Place the tibia or liver in a plastic vial and freeze-dry to a constant weight ( 48 hours).

2. Grind the liver into a powder. The tibia can remain whole.

3. Place 250-350 $\mathrm{mg}$ of ground liver (or whole tibia) in a 25 ml Erlenmeyer flask. Add $4 \mathrm{ml}$ ( $3 \mathrm{ml}$ for the tibia) of nitric acid. Cover and pre-digest at room temperature overnight (12 hours).

4. Set the hot plate (Thermolyne 2200, Thermolyne corp., Dubuque, IA) at $100^{\circ} \mathrm{C}$ and preheat for one-half hour. 
5. Place the samples on the hot plate and cover with a glass plate. Because of the uneven heat distribution, the samples should be rotated 2 or 3 times during the digestion to ensure even heating.

6. Heat the samples for 4-6 hours until all particulate matter is digested. The digested solution should be a pale yellow.

7. Remove from the heat and allow to cool to room temperature.

8. Transfer the digested samples to $25 \mathrm{ml}$ volumetric flasks. Rinse the inside of the Erlenmeyer flasks several times with distilled deionized water to ensure complete transfer of the acid digest. Bring to volume with distilled deionized water.

9. Dilute the samples to the appropriate volumes with distilled deionized water.

10. Analyze mineral concentrations with flame atomic absorption spectrophotometry using a Perkin-Elmer spectrophotometer (Model 3100, Perkin-Elmer (Canada) Ltd., Montreal, PQ). 


\section{APPENDIX 6. BTATISTICAL MFTHODS}

ANOVA: analysis of variance followed by the least significant difference ( $t$ test) for all parameters.

PROC GLM;

CLASS REP ZINC GHORM;

MODEL variable(s) = ZINC GHORM ZINC*GHORM/SS3;

MEANS ZINC GHORM ZINC*GHORM/LSD;

PROC MEANS MEAN STDERR N;

BY ANIMAL;

VAR variable(s); 


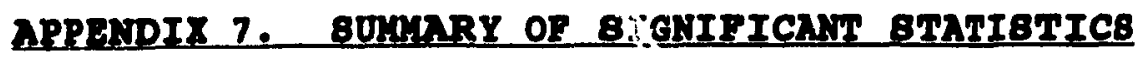

Each table summarizes the ANOVA for the dependent variables tested using the model: VARIABLE = ZINC GHORM ZINC*GHORM.

\begin{tabular}{lcccc}
\hline SOURCE & DF & MEAN SQUARE & F VALUE & PR > F \\
\hline DEPENDENT & VARIABLE: & cumulative food & intake & \\
ZINC & 2 & 145583.300 & 694.03 & 0.0001 \\
GHORM & 1 & 118.073 & 0.56 & 0.4558 \\
ZINC*GHORM & 2 & 27.893 & 0.13 & 0.8757 \\
ERROR & 65 & 209.766 & & \\
\hline MODEL & $R^{2}=0.9553$ & & & \\
\hline
\end{tabular}

\begin{tabular}{lcccc}
\hline SOURCE & DF & MEAN SQUARE & F VALUE & PR > F \\
\hline DEPENDENT & VARIABLE & cumulative weight gain & \\
ZINC & 2 & 92919.268 & 580.56 & 0.0001 \\
GHORM & 1 & 322.978 & 2.08 & 0.1540 \\
ZINC *GHORM & 2 & 34.800 & 0.22 & 0.8052 \\
ERROR & 65 & 160.050 & & \\
\hline MODEL & $\mathrm{R}^{2}=0.9471$ & &
\end{tabular}

\begin{tabular}{lcccc}
\hline SOURCE & DF & MEAN SQUARE & F VALUE & PR $>$ F \\
\hline DEPENDENT & VARIABLE : & cumulative tail & length & \\
ZINC & 2 & 6413.387 & 412.52 & 0.0001 \\
GHORM & 1 & 21.004 & 1.35 & 0.2494 \\
ZINC*GHORM & 2 & 1.799 & 0.12 & 0.8909 \\
ERROR & 65 & 15.547 & & \\
\hline MODEI. & $\mathrm{R}^{2}=0.9271$ & & &
\end{tabular}




\begin{tabular}{lcccc}
\hline SOURCE & DF & MEAN SQUARE & F VALUE & PR $>$ F \\
\hline DEPENDENT & VARIABLE: & liver weight & & \\
ZINC & 2 & 108.865 & 313.52 & 0.0001 \\
GHORM & 1 & 0.235 & 0.68 & 0.4142 \\
ZINC*GHORM & 2 & 0.047 & 0.14 & 0.8738 \\
ERROR & 65 & 0.347 & & \\
\hline MODEL & $\mathrm{R}^{2}=0.9077$ & & & \\
\hline
\end{tabular}

\begin{tabular}{lcccc}
\hline SOURCE & DF & MEAN SQUARE & F VALUE & PR > F \\
\hline DEPENDENT & VARIABLE: & tibia weight & & \\
ZINC & 2 & 0.036 & 290.01 & 0.0001 \\
GHORM & 1 & 0.000 & 0.10 & 0.7515 \\
ZINC GHORM & 2 & 0.000 & 0.26 & 0.7722 \\
ERROR & 61 & 0.000 & & \\
\hline MODEL & $\mathrm{R}^{2}=0.9059$ & & & \\
\hline
\end{tabular}

\begin{tabular}{lcccc}
\hline SOURCE & DF & MEAN SQUARE & F VALUE & PR > F \\
\hline DEPENDENT & VARIABLE: & cartilage epiphyseal & width & \\
ZINC & 2 & 290106.368 & 70.44 & 0.0001 \\
GHORM & 1 & 488.791 & 0.29 & 0.5946 \\
ZINC*GHORM & 2 & 6149.797 & 3.60 & 0.0331 \\
ERROR & 63 & 1708.797 & & \\
MODEL & $\mathrm{R}^{2}=0.8483$ & & & \\
\hline
\end{tabular}




\begin{tabular}{lcccc}
\hline SOURCE & DF & MEAN SQUARE & F VALUE & PR $>$ F \\
\hline DEPENDENT & VARIABLE: & plasma zinC & & \\
ZINC & 2 & 9.176 & 130.68 & 0.0001 \\
GHORM & 1 & 0.444 & 6.32 & 0.0151 \\
ZINC $*$ GHORM & 2 & 0.073 & 1.03 & 0.3630 \\
ERROR & 51 & 0.070 & & \\
\hline MODEL & $\mathrm{R}^{2}=0.8400$ & & & \\
\hline
\end{tabular}

\begin{tabular}{lcccc}
\hline SOURCE & DF & MEAN SQUARE & F VALUE & PR $>$ F \\
\hline DEPENDENT & VARIABLE: & alkaline phosphatase & \\
ZINC & 2 & 41730.047 & 68.60 & 0.0001 \\
GHORM & 1 & 221.250 & 0.36 & 0.5491 \\
ZINC $\star G H O R M$ & 2 & 273.294 & 0.45 & 0.6406 \\
ERROR & 52 & 608.347 & & \\
\hline MODEL & $\mathrm{R}^{2}=0.7351$ & & & \\
\hline
\end{tabular}

\begin{tabular}{lcccc}
\hline SOURCE & DF & MEAN SQUARE & F VALUE & PR > F \\
\hline DEPENDENT VARIABLE: & insulin-like & growth factor I & \\
ZINC & 2 & 2544976.243 & 120.10 & 0.0001 \\
GHORM & 1 & 3340.191 & 0.16 & 0.6927 \\
ZINC*GHORM & 2 & 5570.130 & 0.26 & 0.7697 \\
ERROR & 61 & 21190.604 & & \\
\hline MODEL & $\mathrm{R}^{2}=0.7977$ & & & \\
\hline
\end{tabular}




\begin{tabular}{lcccc}
\hline SOURCE & DF & MEAN SQUARE & F VALUE & PR > F \\
\hline DEPENDENT & VARIABLE : & human growth hormone & & \\
ZINC & 2 & 4.267 & 2.42 & 0.1028 \\
GHORM & 1 & 27.592 & 15.68 & 0.0003 \\
ZINC $*$ GHORM & 2 & 4.670 & 2.65 & 0.0841 \\
ERROR & 36 & 1.760 & & \\
\hline MODEL & $R^{2}=0.4178$ & & & \\
\hline
\end{tabular}

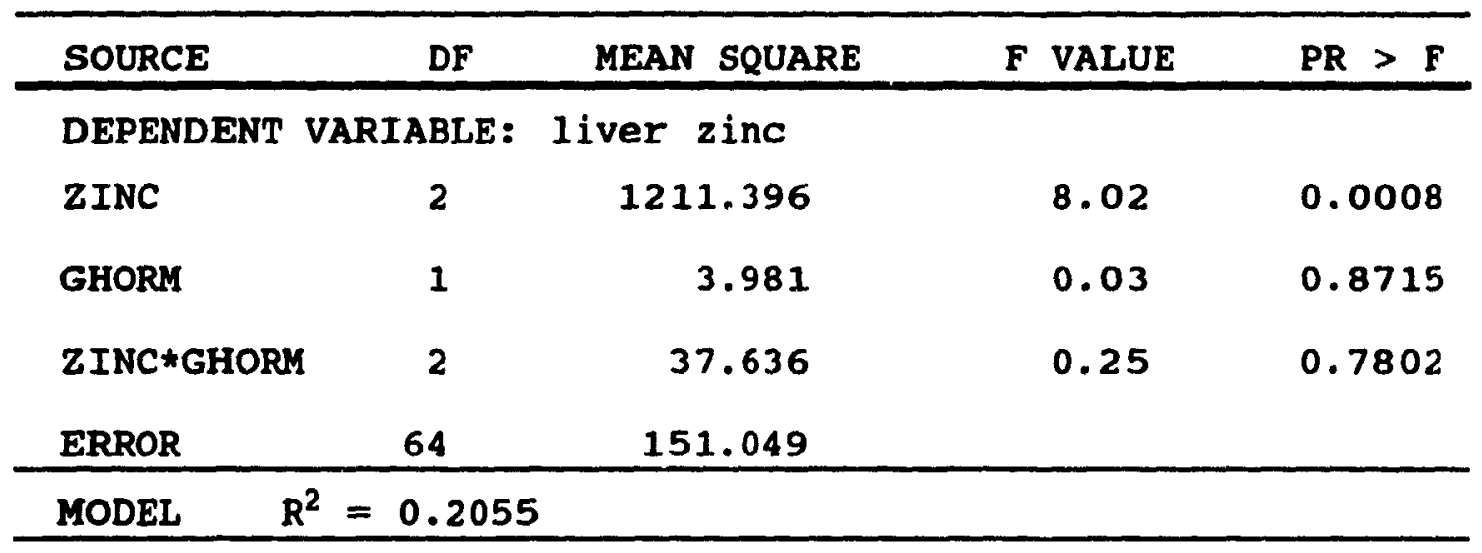

\begin{tabular}{lcccc}
\hline SOURCE & DF & MEAN SQUARE & F VALUE & PR $>$ F \\
\hline DEPENDENT & VARIABLE: & I iver copper & & \\
ZINC & 2 & 91.646 & 16.12 & 0.0001 \\
GHORM & 1 & 0.769 & 0.14 & 0.7143 \\
ZINC*GHORM & 2 & 7.924 & 1.39 & 0.2557 \\
ERROR & 62 & 5.683 & & \\
\hline MODEL & $\mathrm{R}^{2}=0.3580$ & & & \\
\hline
\end{tabular}




\begin{tabular}{lcccc}
\hline SOURCE & DF & MEAN SQUARE & F VALUE & PR > F \\
\hline DEPENDENT VARIABLE: & liver iron & & \\
ZINC & 2 & 105826.253 & 8.08 & 0.0008 \\
GHORM & 1 & 11897.102 & 0.91 & 0.3443 \\
ZINC GHORM & 2 & 63184.573 & 4.83 & 0.0113 \\
ERROR & 61 & 13094.290 & & \\
\hline MODEL & $\mathrm{R}^{2}=0.3159$ & & & \\
\hline
\end{tabular}

\begin{tabular}{lcccc}
\hline SOURCE & DF & MEAN SQUARE & F VALUE & PR $>$ F \\
\hline DEPENDENT & VARIABLE: & tibia zinC & & \\
ZINC & 2 & 208582.288 & 350.19 & 0.0001 \\
GHORM & 1 & 1930.743 & 3.24 & 0.0764 \\
ZINC GHORM & 2 & 3690.974 & 6.20 & 0.0034 \\
ERROR & 65 & 595.629 & & \\
\hline MODEL & $R^{2}=0.9168$ & & &
\end{tabular}

\begin{tabular}{|c|c|c|c|c|}
\hline SOURCE & DF & MEAN SQUARE & F VALUE & $\mathbf{P R}>\mathbf{F}$ \\
\hline \multicolumn{5}{|l|}{ DEPENDENT } \\
\hline ZINC & 2 & 12.177 & 11.92 & 0.0001 \\
\hline GHORM & 1 & 0.948 & 0.93 & 0.3390 \\
\hline ZINC*GHORM & 2 & 4.160 & 4.07 & 0.0216 \\
\hline ERROR & 64 & 1.021 & & \\
\hline MODEL & $R^{2}=0.3455$ & & & \\
\hline
\end{tabular}




\section{BIBLIOGRAPHY}

Aggett, P.J. (1989) Severe zinc deficiency. In: Mills, C. F. (ed.), Zinc in Human Biology, pp. 259-279, Springer-Verlag, N. Y.

Ash, P, M.J.O. Francis (1975) Response of isolated rabbit articular and epiphyseal chondrocytes to rat liver somatomedin. I Endocr 66:71-78.

Ashton, I.K., M.J.O. Francis (1977) An assay for plasma somatomedin: [ ${ }^{3} \mathrm{H}$ ] thymidine incorporation by isolated rabbit chondrocytes. J Endocr 74:205-212.

Ashton, I.K., M.J.O. Francis (1978) Response of chondrocytes isolated from human foetal cartilage to plasma somatomedin activity. I Endocr 76:473-477.

Bettger, W.J., B.L. O'Dell (1981) A critical physiological role of $z$ inc in the structure and function of biomembranes. Life Sci 28:1425-1438.

Bolze, M.S., R.D. Reeves, F.E. Lindbeck, M.J. Elders (1987) Influence of zinc on growth, somatomedin, and glycosaminoglycan metabolism in rats. Am J Physiol 252:E21E26.

Buzina, R., M. Jusic, J. Sapunar, N. Milanovic (1980) Zinc nutrition and taste acuity in school children with impaired growth. Am J Clin Nutr 33:2262-2267.

Cara, J.F., R.L. Rosenfield, R.W. Furlanetto (1987) A longitudinal study of the relationship of plasma somatomedin-C concentration to the pubertal growth spurt. Am I Dis child $141: 562-564$.

Carter, J.P., L.E. Grivetti, J.T. Davis, S. Nasiff et al. (1969) Growth and sexual development of adolescent Egyptian village boys. Am I Clin Nutr 22:59-78.

Castillo-Duran, C., G. Heresi, M. Fisberg, R. Uauy (1987) Controlled trial of $z$ inc supplementation during recovery from malnutrition: effects on growth and immune function. Am $I$ clin Nutr 45:602-608.

Cheek, D.B., R.M. Spargo, H.J. Hay, R.M. Smith (1982) Zinc deficiency in the Aboriginal People of the Northwest of Australia. In: Prasad, A.S. (ed.), clinical, Biochemirale and Nutritional Aspects of Trace Elements, pp. 63-81, Alan R. Liss, Inc., N.Y. 
Chen $X-C$, Yin T-A, He J-S, Ma Q-Y et al. (1985) Low levels of zinc in hair and blood, pica, anorexia, and poor grnwth in Chinese preschool children. Am I clin Nutr 42:694-700.

Cheruvanky, T., M. Castro-Magana, S.Y. Chen, P.J. Collipp, Z. Ghavami-Maibodi (1982) Effect of growth hormone on hair, serum, and urine $z i n c$ in growth hormone-deficient children. Am $\mathrm{I}$ Clin Nutr 35:668-670.

Chesters, J.K., J. Quarterman (1970) Effects of zinc deficiency on food intake and feeding patterns of rats. Br $I$ Nutr 24:1061-1069.

Chesters, J.K., M. Will (1973) some factors controlling food intake by zinc-deficient rats. Br $\underline{\mathrm{J}}$ Nutr 30:555-566.

Clegg, M.S., C.L. Keen, B. Lonnerdal, L.S. Hurley (1981) Influence of ashing techniques on the analysis of trace elements in animal tissue. I. Wet Ashing. Biol Trace Element Res 3:107-115.

Clemmons, D.R. (1989) structural and functional analysis of insulin-like growth factors. Br Med Bull 45:465-480.

Clemmons, D.R., L.E. Underwood, R.N. Dickerson, R.O. Brown et al. (1985) Use of plasma somatomedin-C/insulin-like growth factor I measurements to monitor the response to nutritional ïepletion in malnourished patients. Am J Clin Nutr 41:191198 .

Clemmons, D.R., L.E. Underwood (1991) Nutritional regulation of IGF-I and IGF binding proteins. In: olsen, R.E. (ed.), Annual Review of Nutrition, Vol. 11, pp. 393-412, Annual Reviews Inc., Palo Alto.

Coble, X.D., C.W. Bardin, G.T. Ross, W.T. Darby (1971) studies of endocrine function in boys with retarded growth, delayed sexual maturation, and zinc deficiency. J Clin Endocr $32: 361-367$.

Collipp, P.J., M. Castro-Magana, M. Petrovic, J. Thomas et al. (1982) Zinc deficiency: improvement in growth and growth hormone levels with oral zinc therapy. Ann Nutr Metab $26: 287-290$.

Cossack, 2.T. (1984) Somatomedin-c in zinc deficiency. Experientia 40:498-500.

Cossack, Z.T. (1986) Somatomedin-C and zinc status in rats as affected by $\mathrm{Zn}$, protein and food intake. Br J Nutr 56:163169 . 
Cossack, Z.T. (1988) Effect of $z$ inc level in the refeeding diet of previously starved rats on plasma somatomedin-c levels. I Pediatr Gastroenterol Nutr 7:441-445.

Cousins, R.J. (1979) Regulatory aspects of zinc metabolism in liver and intestines. Nutr Rev 37:97-103.

Daughaday, W.H. (1989) A personal history of the origin of the somatomedin hypothesis and recent challenges to its validity. Pers Biol Med 32:194-211.

Daughaday, W.H., P. Rotwein (1989) Insulin-like growth factors I and II. Peptide, messenger ribonucleic acid and gene structures, serum, and tissue concentrations. Endoce Rev 10:68-91.

Donahue, S.P., L.S. Phillips (1989) Response of IGF-I to nutritional support in malnourished hospital patients: a possible indicator of short-term changes in nutritional status. Am I clin Nutr 50:962-969.

Elders, M.J., B.S. Wingfield, M.L. McNatt, J.A. Lee, E.R. Hughes (1975) Somatomedin and the regulation of skeletal growth. Ann Clin Lab Med 5:440-451.

Emler, C.A., D.S. Schalch (1987) Nutritionally-induced changes in hepatic insulin-like growth factor I (IGF-I) gene expression in rats. Endocrinology 120:832-834.

Fabry, P., T. Braun (1967) Adaptation to the pattern of food intake: some mechanisms and consequences. ProC Nutr SOC 26:144-152.

Fleisen, T., D. Maiter, G. Gercird, L.E. Underwood et al. (1989) Reduction of serum insulin-like growth factor-I by dietary protein restriction is age dependent. Pediatr Res 26:415-419.

Furlanetto, R.w. (1990) Insulin-like growth factor measurements in the evaluation of growth hormone secretion. Horm Res 33 (suppl 4): 25-30.

Ghavami-Maibodi, S.J., P.J. Collipp, M. Castro-Magana, C. stewart, S.Y. Chen (1983) Effect of oral zinc supplements on growth, hormonal levels, and zinc in healthy short children. Ann Nutr Metab 27:214-219.

Gibson, R.S., P.D. Smit Vanderkooy, A.C. MacDonald, A. Goldman et al. (1989) A growth-limiting, mild zinc-deficiency syndrome in some southern ontario boys with low reight percentiles. Am I Clin Nutr 49:1266-1273. 
Golden, M.H.N., B.E. Golden (1981) Effect of zinc supplementation on the dietary intake, rate of weight gain, and energy cost of tissue disposition in children recovering from severe malnutrition. Am I clin Nutr 34:900-908.

Golden, B.E., M.H.N. Golden (1979) Plasma zinc and the clinical features of malnutrition. Am I Clin Nutr 32:24902494.

Granner, D.K. (1990) Pituitary and hypothalamic hormones. In: Murray, R.K., Granner, D.K., Mayes, P.A., Rodwell, V.W., Harper's Biochemistry, 22nd Edition, np. 478-486, Appleton and Lange, Connecticut.

Grant, D.B., J. Hambley, D. Becker, B.L. Pimstone (1973) Reduced sulphation factor in undernourished children. Arch Dis Child 48:596-600.

Greenspan, F.S., C.H. Li, M.E. Simpson, H.M. Evans (1949) Bioassay of hypophyseal growth hormone: the tibia test. Endocrinology 45:455-463.

Halsted, J.A., H.A. Ronaghy, P. Abadi, M. Haghshenass et al. (1972) Zinc deficiency in man: the Shiraz experiment. Am I Med 53:277-284.

Hambidge, K.M., C.E. Casey, N.F. Krebs (1986) zinc. In: Mertz, w. (ed.), Trace Elements in Human and Animal Nutrition, Vol. 2, pp. 1-137, Academic Press, N. Y.

Hambidge, K.M., M.N. Chavez, R.M. Brown, P.A. Walravens (1979) zinc nutritional status of young middle-income children and effects of consuming zinc-fortified breakfast cereals. Am I clin Nutr 32:2532-2539.

Hambidge, K.M., C. Hambidge, M. Jacobs, J.D. Baum (1972) Low levels of $z$ inc in hair, anorexia, poor growth, and hypogeusia in children. Pediatr Res 6:868-874.

Health and Welfare Canada (1990) Nutrition Recommendations, The Report of the Scientific Review Committee, Ottawa, ON.

Holder, A.T., E.M. Spencer, M.A. Preece (1981) Effect of bovine growth hormone and a partially pure preparation of somatomedin on various growth parameters in hypopituitary dwarf mice. I Endocr 89:275-282.

Humbel, R.F. (1990) Insulin-like growth factors I and II. Eur I Biochem 190:445-462.

Hurley, L.S., H. Swenerton (1966) Congenital malformations resulting from $z$ inc deficiency in rats. Proc Soc Exp Biol Yed 
$123: 692-696$.

Isaksson, O.G.P., A. Lindahl, A. Nilsson, J. Isgaard (1987) Mechanism of the stimulatory effect of growth hormone on longitudinal bone growth. Endocr Rev 8:426-438.

Isaksson, O.G.P., A. Nilsson, J. Isgaard, A. Lindahl (1990) Cartilage as a target tissue for growth hormone and insulinlike growth factor-I. Acta Paediatr Scand (Suppl) 367:137141.

Isgaard, J., C. Moller, O.G.P. Isaksson, A. Nilsson et al. (1988) Regulation of insulin-like growth factor messenger ribonucleic acid in rat growth plate by growth hormone. Endocrinology $122: 1515-1.520$.

Isgaard, J., A. Nilsson, A. Lindahl, J.-0. Jansson, 0.G.P. Isaksson (1986) Effects of local administration of $\mathrm{GH}$ and IGF-I on longitudinal bone growth in rats. Am $I$ Physiol 250: E367-E372.

Isley, W.I., L.E. Underwood, D.R. Clemmons (1983) Dietary components that regulate somatomedin-C concentrations in humans. I clin Invest 71:175-182.

Isley, w.L., L.E. Underwood, D.R. Clemmons (1984) Changes in plasma somatomedin-C in response to ingestion of diets with variable protein and energy content. JPEN 8:407-411.

Jackson, M.J. (1989) Physiology of zinc: General aspects. In: Mills, C. F. (ed.), zinc in Human Biology, pp. 1-14, Springer-Verlag, N. Y.

Kemp, S.F., R.G. Rosenfeld, F. Liu, S. Gaspich, R.L. Hintz (1981) Acute somatomedin response to growth hormone: radioreceptor assay versus radioimmunoassay. I Clin Endocr Metab 52:616-621.

Krebs, N.F., K.M. Hambidge, P.A. Walravens (1984) Increased food intake of young children receiving a zinc supplement. Am J Dis Child 138:270-273.

Leveille, G.A. (1972) The longterm effects of meal-eating on lipogenesis, enzyme activity, and longevity in the rat. I Nutr $102: 549-556$.

Lindahl, A., J. Isgaard, L. Carlsson, O.G.P. Isaksson (1987a) Differential effects of growth hormone and insulin-like growth factor I on colony formation of epiphyseal chondrocytes in suspension culture in rats of different ages. Endocrinology 121:1061-1069. 
Lindahl, A., A. Nilsson, O.G.P. Isaksson (1987b) Effects of growth hormone and insulin-like growth factor-I on colony formation of rabbit epiphyseal chondrocytes at different stages of maturation. I Endocr 115:263-271.

Lindahl, A., J. Isgaard, O.G.P. Isaksson (1987c) Growth hormone in vivo potentiates the stimulatory effect of insulinlike growth factor-I on colony formation of epiphyseal chondrocytes isolated from hypophysectomized rats. Endocrinology 121:1070-1075.

Madsen, K., U. Friberg, P. Roos, S. Eden, O. Isaksson (1983) Growth hormone stimulates the proliferation of cultured chondrocytes from rabbit ear and rat rib growth cartilage. Nature 304:545-547.

Maes, M., Y. Amand, L.E. Underwood, D. Maiter, J.-M. Ketelslegers (1988) Decreased serum insulin-like growth factor I response to $\mathrm{GH}$ in hypophysectomized rats fed a low protein diet: evidence for a post receptor defect. Acta Endocr 117:320-326.

Maes, M., L.E. Underwood, G. Gerard, J.-M. Ketelslegers (1984b) Relationship between plasma somatomedin-C and liver somatogenic binding sites in neonatal rats during malnutrition and after short and long term refeeding. Endocrinology $115: 786-792$.

Maes, M., L.E. Underwood, J.-M. Ketelslegers (1983) Plasma somatomedin-c in fasted and refed rats: close relationship with changes in liver somatogenic but not lactogenic binding sites. I Endocr 97:243-252.

Maes, M., L.E. Underwood, J.-M. Ketelslegers (1984a) Low serum somatomedin-C in protein deficiency: relationship with changes in liver somatogenic and lactogenic binding sites. Mol Cell Endocr 37:301-309.

Mahloudji, M., J.G. Reinhold, M. Haghshenass, H.A. Ronaghy et al. (1975) Combined zinc and iron compared with iron supplementation of diets of 6- to 12-year-old village school children in southern Iran. Am J Clin Nutr 28:721-725.

Maiter, D., M. Maes, L.E. Underwood, T. Fliesen et al. (1988) Early changes in serum concentrations of somatomedin-c induced by dietary protein deprivation in rats: contributions of growth hormone receptor and post-receptor defects. I Endocr 118:113-120.

Merimee, T.J., J. Zapf, E.R. Froesch (1982) Insulin-like growth factors in fed and fasted states. I clin Endocr Metab 39 : $999-1002$. 
Moats-staats, B.M., J.L. Brady, L.E. Underwood, A.J. D'Ercole (1984) Dietary protein restriction in artificially reared neonatal rats causes a reduction in insulin-like growth factor-I gene expression. Endocrinology 115:2368-2374.

Nilsson, A., B. Carlsson, J. Isgaard, O.G.P. Isaksson, L. Rymo (1990) Regulation by GH of insulin-like growth factor-I mRNA expression in rat epj.physeal growth plate as studied with insitu hybridization. I Endocr 125:67-74.

Nilsson, A., J. Isgaard, A. Lindahl, A. Dahlstrom et al. (1986) Regulation by growth hormone of number of chondrocytes containing IGF-I in rat growth plate. Nature 233:571-574.

Nilsson, A., J. Isgaard, A. Lindahl, L. Peterson, O. Isaksson (1987) Effects of unilateral arterial infusion of GH and IGFI on tibial longitudinal bone growth in hypophysectomized rats. Calcif Ti-sue Int 40:91-96.

Nishi, Y., S. Hatano, K. Aihara, A. Fujie, M. Kihara (1989) Transient partial growth hormone deficiency due to $z$ inc deficiency. I Am Coll Nutr 8:93-97.

NRC (1978) Nutrient Requirements of Iaboratory Animals, Third Revised Edition, National Research Council. National Academy of Sciences, Washington, D.C.

O'Dell, B.L., F.M. Newberne, J.E. Savage (1958) Significance of dietary zinc for the growing chicken. I Nutr 65:503-518.

Oner, G., N.M. Bor (1978) Serum somatomedin-A activity and insulin levels in zinc deficiency. Nutr Rep Int 18:749-754.

Oner, G., B.B. Bhaumick, R.M. Bala (1984) Effect of zinc deficiency on serum somatomedin levels and skeletal growth in young rats. Endocrinology 114:1860-1863.

Park, J.H.Y., C.J. Grandjean, D.L. Antonson, J.A. Vanderhoof (1986) Effects of isolated zinc deficiency on the composition of skeletal muscle, liver and bone during growth in rats. I Nutr 116:610-617.

Payne-Robinson, H.M., M.H.N. Golden, B.E. Golden, D.T. Simeon (1991) The zinc sandwich and growth. (letter) Lancet $337: 925-926$.

Phillips, A.F., B. Persson, K. Hall, M. Lake ett all, (1988) The effects of biosynthetic insulin-like growth factor-I supplementation on somatic growth, maturation, and erythropolesis on the neonatai rat. Pediatr Res 23:298-305.

Phillips, L.S., T.G. Unterman (1984) Somatomedin activity in 
disorders of nutrition and metabolism. Clin Endocr Metab 13:145-189.

Phillips, L.S., H.S. Young (1976) Nutrition and somatomedin. I. Effect of fasting and refeeding on serum somatomedin activity and cartilage growth activity in rats. Endocrinology $99: 304-314$.

Prasad, A.S. (1982) zinc deficiency in human subjects. In: Prasad, A. S. (ed.), Clinical Biochemical, and Nutritional Aspects of Trace Elements, pp. 4-62, Alan R. Liss, Inc., N. Y.

Prasad, A.S. (1988) zinc in growth and development and spectrum of human $z$ inc deficiency. I Am Coll Nutx 7:377-384.

Prasad, A.S., A. Miale, Z. Farid, H.H. Sandstead, A.R. Schulert (1963) Zinc metabolism in patients with the syndrome of iron deficiency anemia, hepatosplenomegaly, dwarfism, and hypogonadism. I Lab clin Med 61:537-548.

Prasad, A.S., D. Oberleas, P. Wolf, J.P. Horwitz (1969) Effect of growth hormone on nonhypophysectomized zincdeficient rats and of zinc on hypophysectomized rats. I Lab clin Med 73:486-494.

Prewitt, T.E., A.J. D'Ercole, B.R. Switzer, J.J. Van Wyk (1982) Relationship of serum immunoreactive somatomedin-c to dietary protein and energy in growing rats. J Nutr 112:144150 .

Price, D.A., J.M. Wit, S. van Buul-offers, A.M. Korteland-van Male et al. (1979) Serum somatomedin activity ar.a cartilage metabolism in acutely fasted, chronically malnourished, and refed rats. Endocrinology 105:851-861.

Raulin, J. (1869) Etudes cliniques sur la vegetation. Ann Sci Nat Bot Biol Veg 11:93-99.

Reeves, R.D., L. Dickinson, J. Lee, B. Kilgore et al. (1979) Effects of dietary composition on somatomedin activity in growing rats. I Nutr 109:613-620.

Reeves, P.G., B.L. O'Dell (1981) Short-term zinc deficiency in the rat and self-selection of dietary protein level. I Nutr 111:375-383.

Richards, G.E., R.N. Marshall (1983) The effect of growth hormone treatment alone or growth hormone with supplemental zinc on growth rate, serum, and urine zinc and copper concentrations and hair zinc concentrations in patients with growth hormone deficiency. I Am Coll Nutr 2:133-140. 
Robertson, W.W. (1990) Newest knowledge of the growth plate. Clin Orthop 253:270-278.

Ronaghy, H.A., J.G. Reinhold, M. Mahloudji, P. Ghavami et al, (1974) Zinc supplementation of malnourished schoolboys in Iran: increased growth and other effects. Am $I$ clin Nutr 27:112-121.

Ronaghy, H., M.R. Spivey Fox, S.M. Garn, H. Israel et al, (1969) Controlled zinc supplementation for malnourished school boys: a pilot experiment. Am I clin Nutr 22:1279-1288.

Root, A.W., G. Duckett, M. Sweetland, E.O. Reiter (1979) Effects of zinc deficiency upon pituitary function in sexually mature and immature male rats. I Nutr 109:958-964.

Russell, S.M., E.M. Spencer (1985) Local injections of human or rat growth hormone or of purified human somatomedin-c stimulate unilateral tibial epiphyseal growth in hypophysectomized rats. Endocrinology 116:2563-2567.

Salmon, W.D., W.H. Daughaday (1957) A hormonally controlled serum factor which stimulates sulfate incorporation by cartilage in vitro. I Lab Clin Med 49:825-835.

SAS Institute Inc. (1985) SAS User's Guide: Statistics, Version 5 Edition. Cary, N.C.:SAS Institute Inc.

Scheven, B.A.A., N.J. Hamilton (1991) Longitudinal bore growth in vitro: effects of insulin-like growth factor-I and growth hormone. Acta Endocr 4:602-607.

Schlecter, N.L., S.M. Russell, S. Greenberg, E.M. Spencer, C.S. Nicoll (1986b) A direct effect of growth hormone in rat hindlimb shown by artarial infusion. Am I Physiol 250:E231E235.

Schlecter, N.L., S.M. Russell, E.M. Spencer, C.S. Nicoll (1986a) Evidence suggesting that the direct growth-promoting effect of growth hormone on cartilage in vivo is mediated by local production of somatomedin. Proc Nat Acad Sci 83:79327934.

Schoenle, E., J. Zapf, R.E. Humbel, E.R. Froesch (1982) Insulin-like growth factor-I stimulates growth in hypophysectomized rats. Nature 296:252-253.

Schwander, J.C., C. Hauri, E.R. Froesch (1983) Synthesis and secretion of insulin-like growth factor and its binding protein by the perfused rat liver: depeindence ol growth hormone status. Endocrinology 113:297-305. 
skottner, A., R.G. Clark, L. Frylund, I.C.A.F. Robinson (1989) Growth responses in a mutant dwarf rat to human growth hormone and recombinant human insulin-like growth factor I. Endocrinology $124: 2519-2526$.

skottner, A., R.G. Clark, I.C.A.F. Robinson, L. Fryklund (1987) Recombinant human insulin-like growth factor: testing the somatomedin hypothesis in hypophysectomized rats. I Endoce $112: 123-132$.

Smit Vanderkooy, P.D., R.S. Gibson (1987) Food consumption patterns of Canadian preschool children in relation to $\mathrm{z}$ inc and growth status. Am J Clin Nutr 45:609-616.

Solomons, N. W. (1979) On the assessment of $z$ inc and copper nutriture in man. Am I Clin Nutr 32:856-871.

Solomons, N.W. (1982) Biological availability of zinc in humans. Am I Clin Nutr 35:1048-1075.

Solomons, N.W., R.L. Rosenfield, R.A. Jacob, H.H. Sandstead (1976) Growth retardation and zinc nutrition. Pediatr Res 10:923-927.

Spencer, E.M., C.C. Liu, E.C.C. Si, G.A. Howard (1991) In vivo actions of insulin-like factor-I (IGF-I) on bone formation and resorption in rats. Bone 12:21-26.

Srivastava, V.S., M.H. Nadeau, N. Carbonneau (1977) Mineral intakes of university students. Zinc content. I Can Diet AssOC 38:302-308.

Steel, R.G.D., J.H. Torrie (1980) Principles and procedures of statistics of Statistics, 2nd Edition. McGraw-Hill Book Company, N.Y.

Stracke, H., A. Shulz, D. Moeller, S. Rossol, H. Schatz (1984) Effect of growth hormone on osteoblasts and demonstration of somatomedin-C/IGF-I in bone organ culture. Acta Endocr 107: 16-24.

Straus, D.S., C.D. Takemoto (1990) Effect of fasting on insulin-like growth factor-I (IGF-I) and growth hormone receptor mRNA levels and IGF-I gene transcription in rat liver. Mol Endocr 4:91-100.

Swenerton, H., L.S. Hurley (1968) Severe zinc deficiency in male and female rats. J Nutr 95:8-18.

Takahashi, S., M. Kajikawa, T. Jmezawd, S.-I. Takahashi, et ale (1990) Effect of dietary proteins on the plasma immunoreactive insulin-like growth factor-I/somatomedin $C$ 
concentration in the rat. Br I Nutr 63:521-534.

Thissen, J.-P., S. Triest, L.E. Uncierwood, M. Maes, J.M. Ketelslegers (1990) Divergent responscs of serum insulin-like growth factor-I and liver growth hormone (GH) receptors to exogenous $G H$ in protein-restricted rats. Endocrinology 126:908-913.

Thissen, J.-P., L.E. Underwood, D. Maiter, M. Maes et al. (1991) Failure of insulin-like growth factor-I (IGF-I) infusion to promote growth in protein-restricted rats despite normalization of serum IGF-I concentrations. Endocrinelogy $128: 885-890$.

Thorngren, K.-G., L.I. Hansson (1974) Bioassay of growth hormone. I. Determination of longitudinal bone growth with tetracycline in hypophysectomized rats. Acta Endocr 75:653668 .

Todd, W.R., C.A. Elvehjem, E.B. Hart (1934) zinc in the nutrition of the rat. Am I Physiol 107:146-156.

Tusker, H.F., W.D. Salmon (1955) Parakeratosis or zinc deficiency disease in the pig. Proc Soc Exp Biol Med 88:613616.

van Buuls-offers, S., J.L. Van den Brande (1979) Effect of growth hormone and peptide fractions containing somatomedin activity on growth and cartilage metabolism of snell dwarf mice. Acta Endocr 92: 242-257.

Wallwork, J.C., G.J. Fosmire, H.H. Sandstead (1981) Ef fect of zinc deficiency on appetite and plasma amino acid concentrations in the rat. Br J Nutr 45:127-136.

Walravens, P.A., K.M. Hambidge (1976) Growth of infants fed a zinc supplemented formula. Am J Clin Nutr 29:1114-1121.

Walravens, P.A., N.F. Krebs, K.M. Hambidge (1983) Linear growth of low income preschool children receiving a zinc supplement. Am I Clin Nutr 38:195-201.

Williams, R.B., C.F. Mills (1970) The experimental production of zinc deficiency in the rat. Br I Nutr 24:989-1003.

Zapf, J., E.R. Froesch (1986) Insulin-like growth factors/ somatomedins: structure, secretion, biological actions and physiological role. Horm Res 24:121-130. 